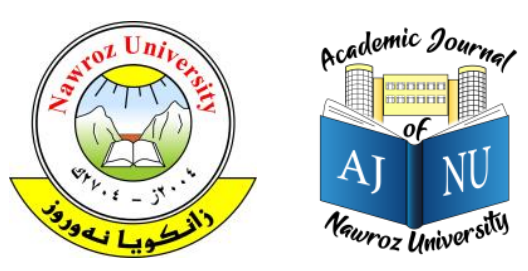

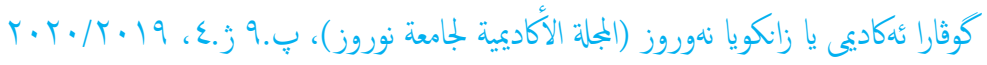

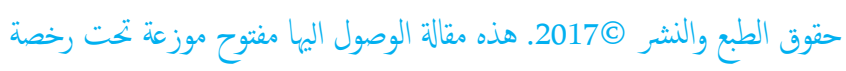

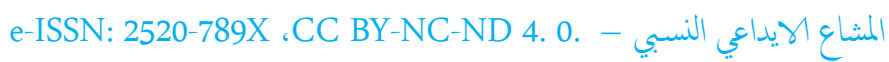

https://doi.org/10.25007/ajnu.v9n4a975

\title{
الأمن الاقتصادي في ظل انتشار فيروس كورونا (كفيد - 19): المستجدات والآثار المستثبلية
}

د. يوسف خليل إبراهيم السبعاوي، اقتصاد دولي، جامعة الدول العربية

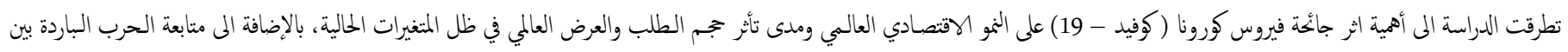

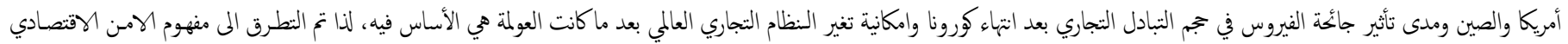

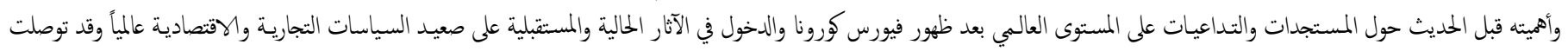

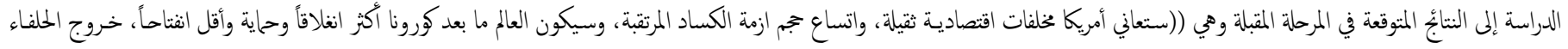

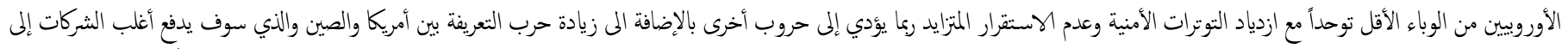

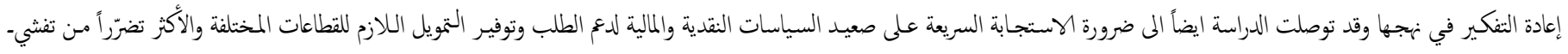

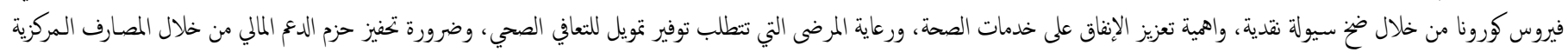

أو من خلال إنشاء محافظ تمويلية)).

الكلمات المثتاحية

الأمن الصحي والتكنولوجي، الحرب البادرة بين أمريكا والصين، كوفيد 19 ، الأمن والاقتصاد

1

الطيران والنقل الجوي:كان قطاع النقل الجوي هو الأكثر تضرراً بأزمة كورونا مع انخفاض معدلات الرحلات حول العالم وبقاء الطائرات على الأرض وإغلاق العديد من المطارات، ومن المتوقع إفلاس بعض الشركات ووصول خسائر شركات الطيران العالمية إلى 200 مليار دولار.

\section{1}

تأتي أهمية البحث من حيث مفهوم الامن الاقتصادي واهميته في ظل اثر جائحة فيروس كورونا (كوفيد - 19) في نمو اقتصاد العالم ومدى تأثر الطلب والعرض العالمي بالمتغيرات المستجدة في مستوى اقتصاد العالم؛ إذ إذ يؤدي الحجر الجغرافي إلى إعاقة الإنتاج وعرقلة الإمداد وإضعاف الطلب العالمي، ومنه الطلب على مصادر الطاقة. وبالمحصلة، سيصيب الفيروس اقتصاد العالم بالشلل مما يوثر على الامن الاقتصادي للدولة، وقد طال تأثيره المادي والمعنوي أسواق المال العالمية التي شهدت انهيارات وأسوأ أداء منذ اندلاع ازمة عام2008 المالية، وبها تعطي أسواق المال مؤشراً سلبياً على شعور المستثمرين بتوجهات تأثير الفيروس في اقتصاد العالم.
منذ بداية ظهور فيروس كورونا (كوفيد- 19) في مدينة اوهان الصينية بشكله الاولي مع الأيام الاخيرة للعام الماضي والاعلان الدولي عنه كوباء عالمي في شهر شباط من عام 2020 من خلال منظمة الصحة العالمية، والعالم يعيش في حالة من الارباك والفزع في جانبي العرض والطلب التي أدّت الى ظهور ازمة اقتصادية عالمية لم تسلم اي دولة سواء آكانت الدول المتقدمة او النامية. إذ إن مستوى الاقتصاد المحلي لدول العالم ظهر أثر فيروس كورونا فيه عبر ما يلي: إعاقة النشاط الاقتصادي، وذلك عبر إعاقة الإنتاج والخدمات والمواصلات والنقل والسياحة والتسوق ، وإضعاف العرض والطلب. تكاليف التصدي والاحتواء، من إنقاذ ودع وإجراءات احترازية لقطاع الصحة وباقي القطاعات الوقتصادية والاجتماعة؛ إذ تعدُّ مرتفعة التكليف. الثقة واليقين، فالارتباك وعدم اليقين يضعفان الثقة، ويؤدي ذلك إلى الإجحام عن الاستثمار والإنفاق والسياحة، ويعدُ انهيار أسعار البترول تأثيرا سلبيا في آراء المستثمرين. 


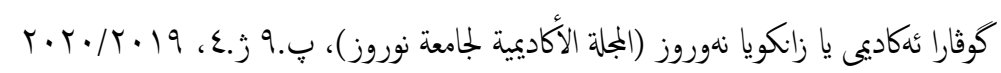

$$
\text { ويبدو أن اقتصاد العالم مقبل لا محالة على تراجع إن لم يكن انكماشا حادا، والتوقعات أولا: مفهوم الامن الاقتصادي وأهميته }
$$
الأولية تشير إلى انخفاض النمو بحدود \% 0.5 - 0.9 إلى \% 1.5 هذا العام، وقد انياً: المستجدات والتداعيات على المستوى العالمي بعد ظهور فيورس كورونا

$$
\text { - }
$$

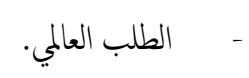

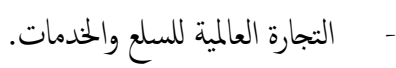

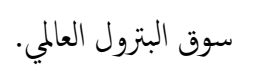

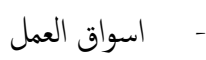

ثالثأ: الآثار الحالية والمستقبلية في صعيد السياسات الاقتصادية

$$
\text { الآثار الحالية في مستوى السياسات المالية والنقدية وتشمل }
$$

$$
\text { آ. الحزم التنشيطية المقدمة من المنظلية الدولية }
$$$$
\text { ب. موابجة حكومات العالم لفيروس كورونا المستجدّ }
$$$$
\text { ج· جهود البنوك المركزية العالمية }
$$

الآثار المستقبلية في مستوى السياسة التجارية والاقتصادية

$$
\begin{aligned}
& \text { أ. الحرب التجارية بين أمريكا والصين } \\
& \text { ب. الحرب الاقتصادية بين أمريكا والصين. } \\
& \text { ج. الاثثار المستقبلية }
\end{aligned}
$$$$
\text { الآثار البعيدة المدى لـCOVID-19 الم }
$$

$$
\text { رابعأ: الخلاصة: متضمنة النتائج والتوصيات المتوقعة }
$$

\section{2. ماهية الامن الاقتصادي وأهيته}

يقصد بمفهوم الأمن الاقتصادي: توافر التدابير اللازمة لتحقيق القدرة المالية المستقلة والفاعالة باستثار عناصر الإنتاج الخختلفة للوصول إلى نظام مالي واستثماري قادر على

$$
\text { إثباع الحاجات الأساسية للفرد. }
$$

وعرف الأمن الاقتصادي بأنه: االندابير والحماية والضمان التي تؤهل الإنسان للحصول على احتياجاته الأساسية من المأكل والمسكن والملبس والعلاج، خاصة في الظروف التي يواجه فيها كارثة طبيعة أو ضائقة اقتصادية وضان الحد الأدنى

$$
\text { لمستوى المعيشة) حمود، } 2002 \text { م.) }
$$
يصل إلى أدنى مستوى له منذ أول أزمة مالية عالمية. وتعدُّ الصين أكبر مستورد للنفط في العالم، والصدمة التي سبها فيروس كورونا للاقتصاد الصيني أضعفت الطلب العالمي على النفط. ومن الملاحظ ان الطلب على لى النفط قبل تفشي الفايروس كان يتزاوح بنحو ال 100 مليون برميل يوي، وانخفاض الطلب عليه بنحو 15 مليون برميل باليوم، والمتوقع ان ينخفض بعقدار 30 مليونا باليوم اذا استمرت مخاطر الفايروس. وتتبين أهمية البحث متابعة تاريخية الحرب الباردة بين أمريكا والصين ومدى تأثير جائحة الفيروس على حجم التبادل التجاري بينها حال انتهاء ازمة كورونا وتغير النظام

$$
\text { التجاري العالمي بعد ماكانت العولمة هي الأساس فيه. }
$$

2.1

تكمن المشكلة من أهمية الأمن الاقتصادي بكونه مرتكزاً رئيسًا للأمن بعهومه الشامل: السياسي والاجتاعي والبيئي. ومدى علاقة جائحة كورونا بالكساد أو القاع والذي يمثل انخفاض الأسعار وارتفاع البطالة وهي اسوأ مرحلة في (Depression) الدورة الاقتصادية ولما لها من تأثير في مستوى الامن الاقتصادي، لذلك العالم يمر بمرحلة شديدة القصوى بسبب جائحة فيروس كورونا وأثبت فشل نظام العولمة بالخروج من مرحلة الكساد في النظام التجاري الحالي بسبب تعدد الازمات المالية

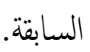

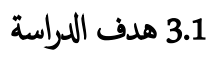

ههدف البحث الى إعطاء تصور نظري حول ماهية الامن الاقتصادي واهميته، كما بهدف البحث المى تحليل أثر جائحة فيروس كورونا ( كوفيد 19) في نمو اقتصاد العالم ومدى تأثر الطلب والعرض العالمي في ظل الهحداث المستجدة. بالإضافة الى تتبع الحرب الباردة بين أمريكا والصين ومدى تأثيد جائحة الفيروس في حجم التبادل التجاري بينها بعد انتهاء ازمة كورونا وتغير النظام التجاري العالمي بعد ماكانت العولمة هي الأساس فيه. وسوف تقسم الدراسة بهدف الوصول إلى النتائج عبر المحاور الآتية: 


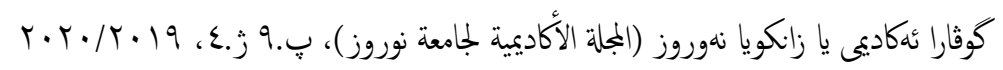

(IMF, 2020).2008

في السياق نسه، توقّ البنك الدولي ( World Bank,2020) بأن ينمو اقتصاد العالم بنحو 2.4 في المائة في عام 2020، إلَّا أنه أشار إلى أن حالة عدم اليقين التي لئي تخيط باقتصاد العالم ما زالت قائمة، ومن تََّّ فإن توجهات البنك الدولي تشير إلى لى إمكانية تعديل هذه التوقعات بما يتمشى بالوضع الحالي والتهديدات الحمتلة التي يسبّها تفنّي الوباء على الرغز من بجود الدول والحزم التحفيزية التي أطلتها المنظات الإقليمة والحكومات والمصارف المركزية العالمية من ناحية أخرى، أشارت منظمة الأم المتحدة ( UN, 2020$)$ بأقل من 2 في المائة عام 2020 مقارنة بتوقعاتها قبل ظهور الفيروس التي بلغت 2.5 في المائة مع احتال قيام المنظمة بمزيد من التغيرات في ظل حالة عدم اليقين الحالية، علماً أن المنظمة أثارت إلى وجود تحديات قائمة التي يمكن أن تكون عائقًاً في تحقيق معدلات النمو التي أشارت إلها منها النزاعات التجارية والجيو سياسية والاضطرابات المالية، إضافة إلى ذلك تداعيات فيروس كورونا على اقتصاد العالم ردّة فعل على تداعيات تفنّي فيروس كورونا على اقتصاد العالم الذي يواجه حالة من عدم اليقين ، وعدم الوصول حتى الآن إلى اكتشاف أمصال لعلاجه. اتجهت المنظات العاملة بقياس النمو إلى مراجعة توقعات النمو الاقتصادي لعام 2020، وتني سيناريوهات أكثر واقعية في الآونة الأخيرة لتقييم تهديد تفشي الوباء ملى اقتصاد العالم، لذلك خفَّت منظمة التعاون الاقتصادي والتنمية OECD

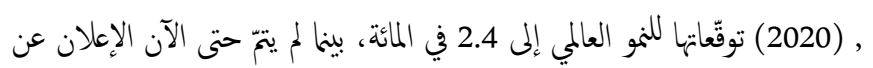
النسب المعدّلة لنمو اقتصاد العالم من قبل المنظات الدولية الأخرى (صندوق النقد () OECD (2020), "Coronavirus)(والبنك الدوليين، ومنظمة الأم المتحدة) ووفقاً لتقديرات منظمة التعاون الاقتصادي لمعدل النمو الاقتصادي العالمي في إطار تقرير آفاق اقتصاد العالم الذي تصدره، يُعزى انخفاض النمو الاقتصادي العالمي إلى تعديل نمو الاقتصاد الأميركي في عام 2020 نتيجة لتفشّي الفيروس من 2.3 في المائة إلى 1.9 في المائة بسبب تراجع الاستهلاك العام والخاص، وعدم اليقين حول أسعار الأصول. أما في الاتحاد الأوربي فن المتوقّ تسجيل نسبة نمو تبلغ 0.8 في المائة عوضاً من 1.2 في المائة بسبب انخفاض الصادرات وتباطؤ الاستهلاك، كذلك عُدِّلت معدلات نمو الاقتصاد الياباني من سالب 0.7 إلى سالب 0.2 في المائة عام 2020، كما عُدِّلت معدلات نمو الاقتصاد الصيني من 6.1 في المائة إلى 4.9 في
وقد عرفت الأم المتحدة الأمن الاقتصادي بأنه: (أن يملك المرء الوسائل المادية التي تَكِكِنه من أن يحيا حياة مستقرة ومشبعة) القليطي، 2007 م (وهو بهذا المعنى يتضمن الأمن الاقتصادي والأمن الاجتاعي، والسياسي؛ لأن الحياة لا تكون مستقرة ومشبعة إلا بتوافر الأمن الاجتاعي والاستقرار السياسي). وبذلك نلمس الارتباط الوثيق بين الأمن والاقتصاد؛ وبين الأمن الاقتصادي والأمن الاجتاعي والسياسي؛ إذ يحتل الاقتصاد مكان الأولوية في الحياة؛ وهو مركز البناء الاجتاعي والسياسي، وبانظام الاقتصاد يكون الاستقرار والأمن، ودون اقتصاد

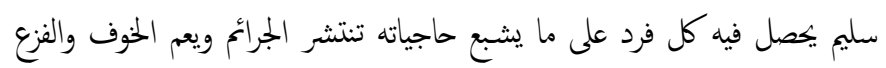
اللذان ها ضد الأمن، وتكمن أهمية الأمن الاقتصادي بكونه مرتكزاً رئيسًا للأمن بمفهومه الشامل: السياسي والاجتاعي والبيئي.

\section{3. المستجدات والتداعيات على المستوى العالمي بعد ظهور فيورس كورونا}

على الرغز من أن الاقتصاد الصيني واجه تراجعاً في معدل نموه خلال العامين السابقين مع انخفاض إنتاجيته بنحو 2 في المائة عام 2019، إلَّا أنه لا يزال يؤدي دوراً محا في اقتصاد العالم بوصفه ثاني أكبر اقتصاد بعد الأميركي، وأكبر اقتصادات مُصدّرة لسلع الصناعات التحويلية؛ إذ وطدت من خلالها الصين علاقها كثريك تُك ترك

$$
\begin{aligned}
& \text { تجاري رئس لدول العالم. (الأم المتحدة (2020) } \\
& \text { ويكن استيضاح التداعيات عبر المؤشرات الآتية: }
\end{aligned}
$$

شهد نمو اقتصاد العالم تباطؤاً بحدّ ذاته قبل ظهور فيروس كورونا نتيجة للتحدّيات التي تواجحه والمتمّلة في التوّرات التجارية بين الصين وأمريكا، والمخاطر الجيوسياسية، فضلاً عن تقلّب الأوضاع في بعض دول العالم. كانت المنظلات الدولية قد خفضت توقّانها بشأن النمو الاقتصادي العالمي قبل تفشّي وباء كورونا ؛ إذ عدل صندوق النقد الدولي توقّاته من 3.3 في المائة إلى 3.2 في المائة في عام 2020 في أعقاب ظهور الفيروس، فيا يتجه حالياً إلى تعديل هذه التوقّات بعد انتشار فيروس كورونا آخذاً بالاعتبار تأثيره السلبي في جانبي العرض والطلب العالميبن، خصوصاً بعد تباطؤ محدّدات الطلب العالمي المتمّلّة في الاستهلاك والاستثمار العالميين، بالإضافة إلى حركة التجارة العالمية التي تعرضت لشلل عقب إغلاق الدول لحدودها، وتقييد انتقالات السلع والأفراد؛ إذ أشار في هذا الصدد إلى دخول اقتصاد العالم إلى ركود أعمق من تلك التي شهدها خلال ازمة العالم في عام 


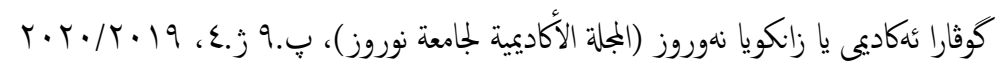

التي ستركز أغلها في شرق آسيا مثل الصين، واليابان، وكوريا الجنوبية التي في الأساس من أوائل الدول التي أصابها الوباء بالإضافة إلى الثركات الصناعية الكبرى في الدول الأوروبية وأمريكا. عليه فإن انقطاع الإمدادات نتيجة لتفشي الفيروس، من المتوقُّ أن يؤدّي إلى تباطؤ الانتاج، مما يؤدّي إلى صدمات عرض أكبر في دول العالم. أنظر الشكل رقة (2) في ملحق البحث. 3.3 التجارة العالمية للسلع والحدمات أصيبت حركة التجارة العالمية بالشلل خلال مدة وجيزة من تفشي فيروس كورونا ما أثّر بدوره في الصادرات والواردات؛ إذ توقّت منظمة التجارة العالمية تباطؤا بحركة التجارة السلعية حول العالم في الأجل القصير نتيجة للاضطرابات الناتجة عن تداعيات الفيروس لظروف عدم اليقين وإغلاق الحدود بين الدول، بما في ذلك دول

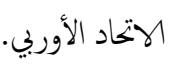
تشير التقارير إلى أن تجارة الخدمات في العالم تشهد انخفاضا ملحوظا منذ عام 2019، بمعدّل نموها من 4.7 في المائة في الربع الأول لعام 209، إلى نحو 2.8 في المائة في الربع الثالث لعام 2019، ومن المتوقّ أن يتواصل الانخفاض لا سيا أن تفشي فيروس كورونا ثثّر سلباً في الأجل القصير لعدد من الخدمات المهمة التي تمثل أساساً لميزان مدفوعات الدول مثل خدمات النقل الجوي، وخدمات السياحة اللتين تعدان من أكثر القطاعات تأثراً بتفشي الفيروس. من الامثلة، سجل مقياس تجارة خدمات النقل الجوي للركاب ومقياس تجارة خدمات نقل السلع 93.5 و74.3 نقطة على التوالي؛ إذ يغطي المؤشّران التطوّرات حتى يناير 2020 ويعكسان إلى حدّ ما الجهود التي بُنلت في ذلك الوقت لتقليل انتشار المرض، خصوصاً في الصين والدول المجاورة كاليابان

$$
\text { وكوريا الجنوبية. (2020) (WTO). }
$$

بالنسبة لقطاع السياحة، أن السائحين الصينين من أهم جنسيات السائحين في عدد من دول العالم؛ إذ إن انتشار الفيروس من المؤكّد أن يخنض الإيرادات المتوقعة لشركات السياحة حول العالم التي تُعدّ أسواقاً سياحية للصين من أهمها اليابان،

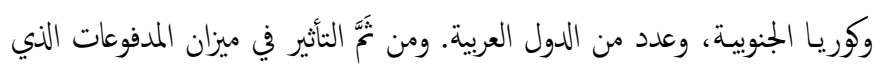
لن ينحصر فقط في الأثر السبي في قطاع السياحة، بل سيطال كذلك قطاع الفنادق الذي سجّل خسائر في الصين؛ إذ ألغيت غالبية ججوزات الفنادق بعد الإعلان عن تفشي الفيروس مماكبد القطاع السياحي في الصين خسائر فادحة. انظر

$$
\text { للشكل رة (3) في ملحق البحث. }
$$

المائة، ولا تزال هناك مخاطر سلبية أخرى على اقتصاد العالم بالنظر إلى حالة عدم اليقين التي تسود العالم في هذه المدة." انظر للشكل رق (1) في ملحق البحث. 2.3 ظهر فيروس كورونا في وقت تحتل فيه الصين مكانة اقتصادية مرموقة في اقتصاد العالم، ومن ثم انتشر إلى أكبر الاقتصادات مساهمة وأكثرها تأثيراً في نمو اقتصاد العالم مثل أمريكا، واليابان، والاتحاد الأوربي الذين تبلغ مساهتهم مجتمعة ب55 \% من ناتج اجالي العالم، وأكثر من 60 \% من إجالي تصنيع العالم، ونخو 50\% من الصادرات المصنّعة حول العالم، كذلك طال الفيروس منطقة الشرق الأوسط بالأخص إيران

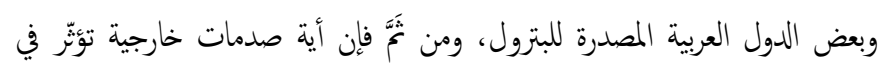
الدول المذكورة آنفا، تنعكس تداعياتها على سلاسل العرض في باقي دول العالم وتمثل

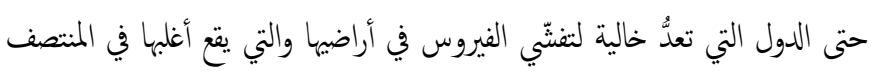

$$
\text { الجنوبي من العالم.(( موقع الأونكتاد ( } 2020 \text { ). }
$$

يبطئ تفتّي الفيروس الطلب العالمي كونه يخلق نوعاً من الهلع وعدم اليقين على مستوى القطاع العائلي وقطاع الأعال باستثناء الطلب على المستلزمات الطبية والأجزة والأمصال الذي من المتوقّ أن يزداد بشكل كير مقارنة بالطلب على السلع والخدمات الأخرى التي تأثرّت بالفيروس مثل النفط، وخدمات السياحة والنقل الجوي، وتقييد مرور السلع والمسافرين من خلال الحدود حتى في دول الاتحاد الأوربي. كما تمثّل منتجات وصادرات الدول الكبرى المثتئّة بتفشي فيروس كورونا،

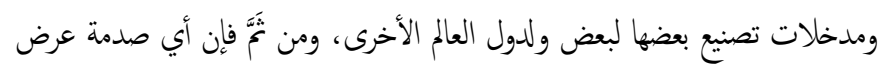
تنتج عن الوباء سوف تصيب العالم كله، من خلال العدوى عبر سلاسل القيمة

$$
\text { الدولية وبالأخص السلع الوسيطة. }
$$

من جانب آخر ، تمتدّ تداعيات الفيروس لتصيب جانب العرض العالمي من خلال محركات الطاقة التشغيلية (العمالة، ورأس المال) التي أصبحت غير مستغلة بكمل طاقتها الانتاجية طوال مدة تفشي المرض نتيجة للسياسات الاحترازية والتدابير الوقائية المُتِخذة مثل عمليات الحجر الصحي، وحظر التجوال في بعض الدول المتقدّمة والاقتصادات الناشئة، ونتيجة لحالات الإصابة والوفيات التي تركت أثراً في

$$
\text { الأداء الاقتصادي خلال الربع الأول من عام } 2020 .
$$

في السياق نقسه، يعدُّ قطاع تصنع السلع الممقّرة (السيارات، الأدوات الإلكترونية والكهربائية،... إخخ) من قطاعات رئيسة في العالم، بالأخص في الاقتصادات الناشئة 


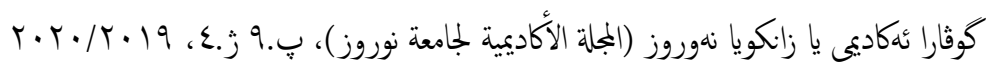

2020، من جانب آخر عُدِّلت توقعات الزيادة في مستويات المعروض النفطي العالمي في عام 2020 بمقدار 0.09 مليون برميل يومياً ليصل إلى نحو 1.99 مليون برميل يومياً، والجدير بالذكر أن المنظمة راجعت الإنتاج بالزيادة في كل من روسيا، وتايلاند، وإندونيسيا، وعُمان، في حين عُدِّل الإنتاج بالنقصان في أمريكا، والصين، والمكسيك، وكولومبيا، والنرويج، وأذربيجان، وماليزيا. أشارت منظمة الأوبك في تقريرها الشهري الصادر في مارس 2020، أنظر (OPEC (2020)() إلى أن أسواق المنتجات النفطية في أمريكا والاتحاد الأوربي تأثّرت سلبياً بتفشي الوباء، لا سيا وقود الطائرات، نتيجة للاضطرابات التي لحتت بقطاع النقل الجوي بعد انتشار الفيروس خارج الصين، كما تأثّز صافي إيرادات مصافي تكرير البترول في عدد من مناطق العالم خاصة في آسيا، إضافة إلى تأثر قطاع النقل النفطي سلباً بالتطورات المرتبطة بتفشي فيروس كورونا ، مما أدّى إلى توقعات غير تفاؤلة بشأن مستقبل إنتاج ونقل النفط العالمي؛ إذ أدّت الاضطرابات النامة عن التدابير الرامية إلى وقف تفشّي الوباء في الصين إلى انخفاض حادّ في الحركة الاقتصادية، بما في ذلك تشغيل المصافي، مما أثّر في واردات النفط الخام وأسعار

$$
\text { الشحن. أنظر للشكل رقٌ (5) في ملحق البحث. }
$$

\section{3}

تأثرّت القوى العاملة في قطاعي السياحة والنقل بوصفها أكثر القطاعات تضرّراً من تفشي الفيروس، غير أن الأثر امتدّ ليشمل العاملين في مجالات عمل أخرى ؛ إذ تأثّرت لاحقاً بالتدابير الاحترازية التي أعلتها الحكومات بإغلاق المحال التجارية، ومناطق التسوّق ، والأماكن التزفيهة، علماً أن العاملين في هذه القطاعات غالبيتهم من

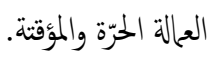

وعليه فإن تداعيات فيروس كورونا سوف تنعكس على سوق العمل كونها ستؤدّي إلى تسريح العملة المؤقتة، التي تتقاضى أجوراً ضئلة، فضلاً بتخفيض ساعات العمل، ومن تًََّ انخفاض دخل الفرد للعالة المؤقتة. في المقابل سوف يكون مستوى تأثّر العالة في الوظائف الدائمة في القطاعين العام والخاص أقلّ نسبياً خلال الأجلين القصير والمتوسط، نظراً لوجود بدائل أخرى للتواصل، مثل العمل عن بُعد، والعمل من المنزل باستخدام التقنيات الحديثة المتاحة الذي دخل حيّز التنفيذ تزامناً مع

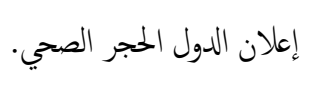

ليس من المتوقّ أن يستردّ القطاع السياحي عافيته خلال المدة الباقية من عام 2020، إذ قد يمثدّ الأثر إلى نهاية عام 2021، فرما يبدأ في استرداد عافيته لكن ليس بمستوى ما كان عليه قبل الأزمة حتى في حال انحسار الفيروس، نظراً للانطباع السلبي حول المرض الذي سيطر على السياح في أنخاء العالم. في هذا الصدد، من المتوقّ أن يتغيّر ترتيب دول العالم في مؤتّر تنافسية السفر والسياحة الذي يصدره المنتدى الاقتصادي العالم World Economic Forum (2020)()، فالصين التي تحتل المركز رقز 13 بنحو 26.7 نقطة في المؤشر من المتوقّع أن تتزاجع في عام 2020، وكذلك الحال بالنسبة إلى الدول التي تشهد معدلات إصابة مرتفعة بالفيروس وبالأخص دول الاتحاد الأوربي وأمريكا نتيجة للضوابط والقيود التي فرضتها الدول القاضية بمنع الدخول والخروج، بالإضافة إلى إغلاق المناطق السياحية والتزفيبية إلى حين إثعار آخر ، وفقاً لمقياس تجارة المدمات

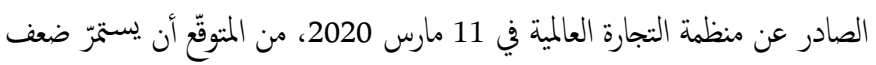
معدل نمو تجارة الخدمات العالمية بسبب الفيروس؛ إذ من المربح أن ينخض أكثر في الأشهر القليلة. "WTO DG welcomes G7" , 2020)" أنظر للشكل رخ (4) في ملحق البحث.

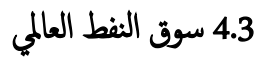
في هذه الجزئية سنتناول الآثار التي تركها فيروس كورونا على سوق النفط العلمي من خلال تسليط الضوء على جانبي الطلب والعرض للسوق فضلاً عن البنية التحتية لقطاع النفط المتمّلّة في نقل البترول التي طالتها تداعيات تفشي كورونا. قبل تفشي كورونا سجلت الزيادة في مستويات الطلب العالمي على النفط انخفاضاً في عام 2019 لتصل إلى نحو 0.083 مليون برميل يومياً، بما يعكس تباطؤ النشاط الاقتصادي العالي في أعقاب انتشار فيروس كورونا، راجعت منظمة الأوبك تقديراتها لمعدل نمو الطلب العالمي على النفط، بالخفض في شهر مارس إلى نخو 0.06 مليون برميل في اليوم، مما يعكس تباطؤ النمو الاقتصادي العالمي المرتبط بانتشار

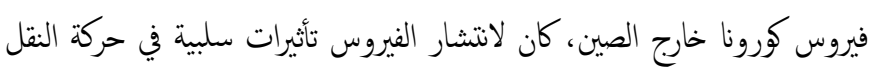
والطلب على الوقود في عدد من القطاعات الاقتصادية، ومن أهمها الصناعة في مختلف البلدان والمناطق الأخرى خارج الصين، مثل اليابان وكوريا الجنوبية دول منظمة التعاون الاقتصادي والتنمية في أوروبا والشرق الأوسط. بناء عليه، فمن المتوقع أن يبلغ الطلب الإجلالي على النفط 99.73 مليون برميل في اليوم في عام 


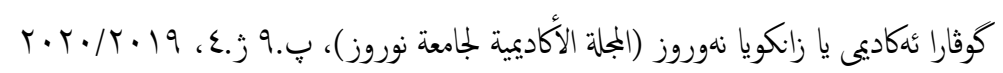

قائمة، ببنا ستقدّم مؤسسة التنمية الدولية نخو 1.3 مليار دولار، والبنك الدولي للإنشاء والتعمير نحو 2.7 مليار دولار، في حين تشارك محفظة الإقراض الحالية بنحو 2 مليار دولار، والجدير بالذكر أن التمويل سيُستخدم في الاستجابة للطلبات الفورية لدول الأعضاء لتمويل احتياجاتها، وأيضاً تقليل الآثار السلبية الحتملة اللفيروس التي سوف تشارك في تعزيز مثانة أنظمة الصحة العامة، بما في ذلك احتواء الأمراض وتشخيصها وعلاجها، ودعز القطاع الخاص، كما وافق المجلس التنفيذي للبنك في 2 أبريل 2020 على حزمة أخرى من الدع بتمة 1.9 مليار دولار أميركي لدع بهود الدول في مواجهة فيروس كورونا، كما أبدى البنك الدولي استعداده لمضاعفة حجم الدز إلى ما يقارب 160 مليار دولار أميركي خلال المخسة عشر شهراً World Bank (2020).المقبلة كما أعلن البنك الإسلامي للتنمية عن تخصيص وإتاحة تسهيل ائتماني وتدخلات داعمة بقيمة 730 مليون دولار للحدّ من الآثار الصحية والاجتاعية والاقتصادية السلبية لفيروس كورونا، كما ستشارك المؤسسة الدولية الإسلامية لتمويل التجارة بنحو 300 مليون دولار، إضافة إلى 150 مليون دولار من مؤسسة التعاون الإسلاي لتأمين الاستثمار وتمويل الصادرات، وسيقدم التمويل إلى كل من القطاعين العام والخاص من أجل الحدّ من انتشار الوباء وتقليل أثره في الدول الأعضاء، بحيث سيقدم التمويل على شكل منح، وموارد ميسرة، وتويل تجاري، وإقراض للقطاع الخاص، وتغطية

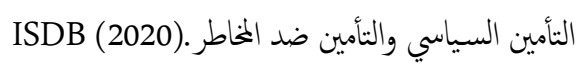
من جانها اتخذت مجموعة العشرين برئاسة المملكة العربية السعودية بمموعة من التدابير وحزم التحفيز المالي في هذا الإطار، كما أعلنت قة بموعة العشرين الطارئة الافتراضية التي عُقدت خلال شهر مارس 2020 عن ضحّ 5 تريليونات دولار في اقتصاد العالم؛ إذ توظف لدئ الإجراءات والتدابير الاحترازية للحدّ من الآثار الاجتاعية والاقتصادية والمالية لفيروس كورونا. كما كبّف وزراء المالية ومحافظو البنوك المركزية لمجموعة العشرين اجتاعاتهم الاستثنائية بهدف تشجيع الجهود الدولية

$$
\text { على عدد من الأصعدة كما يلي: }
$$

الاجتماع الافتراضي الاستثنائي الأول لمحافظي البنوك المركزية ووزراء مالية مجموعة

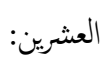

اجتع وزراء مالية بمحوعة العشرين ومحافظو البنوك المركزية يوم الاثنين 23 مارس 2020، برئاسة بمموعة العشرين السعودية، لمناقشة تأثير وباء COVID-19 في تركي
وقد أشارت منظمة العمل الدولية (2000، ILO)' إلى أن التداعيات الاقتصادية للفيروس قد تتسبّب في فقدان ما يصل إلى 25 مليون وظيفة في العالم. استندت توقّات المنظمة المى ثلاث فرضيات وهي: الأولى مثفائلة تشير إلى أن عدد العاطلين من العمل بسبب تفشي الفيروس سيصل إلى 5.3 مليون عاطل، وتشير الفرضية الثانية غير المتفائلة إلى فقدان 24.7 مليون شخص وظائنهم في المدة القادمة، أما الفرضية المعتدلة فتتوقع أن يصل عدد الوظائف المفتودة إلى 13 مليون وظيفة. أنظر شكل رقٌ (6) في ملحق البحث.

\section{4. الآثار الحالية والمستقبلية في صعيد السياسات الاقتصادية}

بجرّد أن أعلنت منظمة الصحة العلمية أن فيروس كورونا وباء عالمي، اتجهت المنظمات الدولية إلى توظيف مواردها لمصلحة دول الأعضاء للحدّ من انتشار الوباء؛ إذ أنشأت المنظمة بالتعاون مع مؤسسة الأم المتحدة، ومؤسسة الأعمال الخيرية السويسرية، صندوقا للاستجابة التضامنية لمساعدة الدول الأعضاء على مواجهة الفيروس؛ إذ يتيح الصندوق، وهو الأول من نوعه دولياً للأفراد والشركات والمؤسسات الخاصة في أي مكان في العالم المساهة بشكل مبانر في جهود الاستجابة العالمية. وعلى صعيد السياسات التجارية قُِّّمت على ثلاثة محاور هـا: 1.4 الآثار الحالية في صعيد السياسات المالية والثقدية وتشمل 1.1.4 الحزم التحفيزية المقدمة من المنظات الدولية تبنّت المنظات الدولية والإقليمة تدخلات على نطاق واسع لتقديم الدع لدولها الأعضاء؛ إذ أعلن صندوق النقد الدولي حزمة تدخلات بقيمة IMF (2020), تريليون دولار، من بيها 50 مليار دولار في إطار التسهيلات التمويلية الطارئة التي يقدما لدوله الأعضاء (Rapid-Disbursing Emergency Financing) (منخفضة الدخل، والأسواق الناشئة)، تشمل تدخلات بواقع 10 مليار دولار كقروض بفائدة صفرية للدول الأشدّ فقراً من خلال تسهيل الائمان السيع ( The .(Rapid Credit Facility من جانب آخر، أعلنت بموعة البنك الدولي في 17 مارس 2020 عن حزمة تمويلية لدع الدول الأعضاء بقيمة 14 مليار دولار لمواجية فيروس كورونا، بجيث ستشارك المؤسسات التابعة للمجموعة في تقديم هذا الدع، وسوف ستشارك مؤسسة التمويل الدولية بتقديم 8 مليارات دولار، منها نحو 2 مليار دولار عبارة عن تسهيلات تجارية 


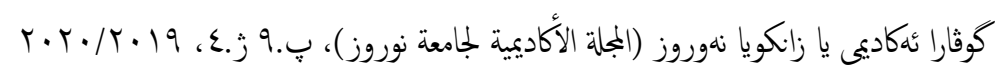

دول العالم لموابجة الوباء وتحديد الفجوات القائة بهدف صياغة تدخلات فعًالة للمواجحات، ورصد الموارد اللازمة لذلك ومطالبة الدول بالافتاح فيها يتعلّق بمشاركة المعلومات ذات العلاقة كافة. تخفيف النداعيات على الاقتصادات الفتيرة: طالب صندوق النقد الدولي والبنك الدولي الدائين الثنائين بوقف تحصيل الديون من الدول المؤهلة للاقتزاض من

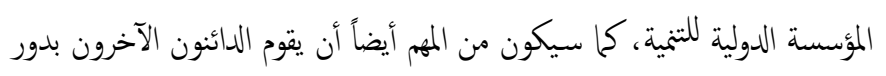
مماثل على وفق دور مأمول من بمموعة العشرين، لبناء توافق في الآراء حول مساندة الأعضاء الأشدّ فقراً، على تجاوز هذه الأزمة لا سيا فيا يتعلّق بدول نادي باريس. تدابير عاجلة: أكّدت العديد من البلدان أهمية التزكيز في المرحلة الحالية في التدابير العاجلة لضمان توفير السيولة من خلال ترتيبات مبادلة العملات ما بين البنوك المركزية SWAPS Arrangements وبخاصة الترتيبات الدولارية، وتوسيع نطاقها عالمياً لضمان توفير السيولة. وضرورة التزكيز في الترتيبات الطارئة الداعمة للسيولة من البنوك المركزية وبخاصة في الدول النامية والأسواق الناشئة والبلان منخفضة

$$
\text { الدخل. (g20.org/ar) }
$$

\subsection{4 مواجمة حكومات العالم لفيروس كورونا المستجدّ:}

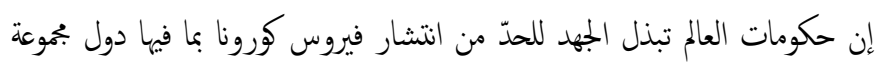
العشرين، والاتحاد الأوربي، وبعض الدول الإفريقية، ودول أميركا اللاتينية، وما يجدر بالذذر أن أغلب حزم التحفيز الملالي التي أعلنتها الدول وُبِّتَت إلى تقوية برامج المماية الاجتاعية، مثل التحويلات النقدية المباشرة لدع الأسر الفقيرة وذوي الدخل

$$
\text { المحدود، بالإضافة إلى دع برامج الضمان الاجتمعي والضان الصحي. }
$$

في هذا الصدد أعلنت أمريكا عن حزمة تحفيز تعدُّ الأكبر في تاريخها لدع الأفراد وقطاع الأعمال في موابجة التباطؤ الاقتصادي الناتج عن تفشي كورونا ، بقيمة تريليوني دولار. أما أستراليا فقد وافقت حكومتها على بمموعتين من حزم التحفيز الاقتصادي بقيمة 189 مليار دولار أسترالي ما يعادل 9.7 في المائة من الناتج المحلي الإجلالي، بحيث تُوجَّه لدئ الأسر الفتيرة، والمثروعات الصغيرة والمتوسطة. (2020) (IMF) كما قدّمت الحكومة الكندية حزمة من التحفيزات الضريبية بما يعادل 0.05 في المائة من الناج المحلي الإجلالي لدع النظام الصحي، بما يشمل الاختبارات الطبية، وتطوير اللقاحات، والإمدادات الطبية. بالإضافة إلى ذلك قدمت هذه الأخيرة دعاً للأسر الفقيرة بقيمة 23.6 مليار دولار بما يعادل 1 في المائة من الناتج المحلي
اقتصاد العالم وتنسيق جهوده لمواجهة هذا التحدّي العالمي، خلال الاجتلاع اتقق وزراء مالية بمموعة العشرين ومحافظو البنوك المركزية على الآتي:

رصد تطوّر وباء COVID-19 عن كثب، بما في ذلك تأثيره في الأسواق والظروف الاقتصادية، واتخاذ المزيد من الإجراءات لدع الاقتصاد خلال هذه

$$
\text { المرحلة وبعدها. }
$$

وضع خطة عمل مشتركة لمجموعة العشرين بتحديد الإجراءات الفردية والجماعية التي اتخذتها مجموعة العشرين وستتخذها للاستجابة لوباء .COVID-19

دع دور صندوق النقد الدولي، والعمل عن كثب مع بموعة البنك الدولي وغيرها من المؤسسات المالية الدولية، في حشد جميع الموارد المتاحة، واستكثاف التدابير الإضافية اللازمة لدع الاستقرار المالي وتخفيف الثروط المفروضة على السيولة من أجل الناشئة والاقتصادات النامية.

خلص الاجتاع الافتراضي الطارئ لمجموعة العشرين إلى ضرورة تكثيف الجهود المشتركة لمجموعة العشرين، والعمل بجزم وبطريقة منسّة لتقديم الدع اللازم، بما يعمل على استقرار اقتصاد العالم، واستعادة الثقة، والحدّ من الآثار الاقتصادية السلبية، وضرورة قيام بموعة العشرين بتعزيز تعاونها في التصدّي لوباء COVID-19 ووضع رؤية للاجراءات المتوسطة والطويلة الأجل، التي من شأهها أن تعزّز الانعاش السريع في الاقتصاد وتخفز إمكانية تحقيق نمو اقتصادي أقوى.(g20.org/ar/ ). الاجتماع الافتراضي الاستثنائي الثاني لمحافظي البنوك المركزية ووزراء مالية مجموعة العشرين: عُقَِّ الاجتماع الثاني لوزراء المالية ومحافظي البنوك المركزية لمجموعة العشرين، يوم الثلاثاء الموافق 31 مارس 2020 افتراضياً عبر تقنية الفيديو كونفران، من أجل الاتفاق على خارطة طريق لتنفيذ التزامات قة قادة بموعة العشرين الافتراضية التي عقدت في 26 مارس 2020 برئاسة بمحوعة العشرين السعودية، وذلك بما يشمل

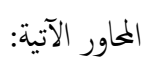
جهود التعاون الدولي المستقبلية لمواجهة تداعيات فيروس كورونا المستجد: تكليف G20 ( منظمة الصحة العالمية في إطار مبادرة الجاهزية العالمية لموابحة الأوبئة (Global Pandemic Preparedness Initiative 


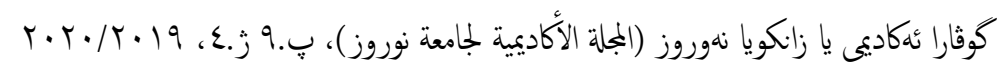

الصحة، إضافة إلى فتح خط ائتمان جديد يوفّر دع السيولة لجميع الشركات العاملة في قطاع السياحة. على الرغ من عدم اكتشاف حالات إصابة كثيرة في أفريقيا جنوب الصحراء، إلَّا أن الدول الأفريقية اتخذت إجراءات احترازية تحسباً لثفاقم الأزمة. في بنين على سبيل المثال، وصلت حزمة التدابير المالية التي قدمتها السلطات إلى نحو 17 مليون دولار أميركي (0.1 في المائة من الناتج المحلي الإجلالي)، وتتطلع السلطات إلى تعزيز التدابير بالاعتماد على دع المانحين. وفي بوتسوانا أرصدت الحكومة نخو 0.25 في المائة من الناتج المحلي الإجالي لموابجة تداعيات الأزمة. من ناحية أخرى، تدرس الحكومة في بوركنافاسو التدابير المالية الممكن اتخاذها والتي من شأنها معالجة الآثار الاجتاعية والاقتصادية من تفشي الفيروس؛ إذ أعدَّت خطة للاستجابة لحالات الطوارئ في القطاع الصحي، وتعزيز القدرات البشرية والتقنية للمستشفيات العامة، وتوسيع قدرات الكشف عن الحالات المصابة بالفيروس، وشراء الإمدادات الطبية لتيسير تنفيذ تدابير النظافة الصحية. أما في بورندي، فلم يعلن رسمياً عن أي تدابير مالية لعدم اكتشاف حالات إصابة، إلَّا أن الحكومة أعلنت أن الحطة الإسعافية الطارئة قد تكلّف نحو 14.5 مليون دولار (0.5 في المائة من الناتج المحلي الإجلالي) مع إمكانية تعزيز الدع المالي في حال تمّ الإبلاغ عن أي حالة إصابة بالفيروس. إلى جانها الكاميرون التي أعلنت حكومتها عن حزمة مالية بلغت 11 مليون دولار (0.1 في المائة من الناتج المحلي) عبر البرنامج الإسعافي الطارئ الذي أعلتنه حكومة الكامرون. وتتزامن الزيادة في الإنفاق الصحي وغيره من النفقات المتعلّقة بالأزمات مع انخفاض الإيرادات البترولية وغير البترولية بسبب تباطؤ اقتصاد العالم.

3.1.4 جمود المصارف المركزية العالمية:

على مستوى المصارف المركزية العالمية، خفض عدد كير منها معدلات الفائدة النقدية لتحفيز الطلب الكليّ، لموابجة فيروس كورونا وفي مقدمتها مجلس الاحتياطي

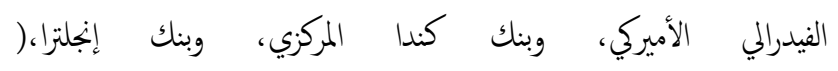
(www.federalreserve.gov نصف نقطة مئوية في 3 مارس 2020 ردة فعل على المخاطر المتنامية بسبب الفيروس. ففي أمريكا وبناء على القرار الطارئ للجنة السياسات النقدية ببنك الاحتياط الفيدرالي تمّ تبني حزمة واسعة من القرارات لتيسير السياسة النقدية،
الإجالي، فضلاً عن مبلغ 58.8 مليار دولار (2.5 من الناتج المحلي الإجالي) لدع الشركات الصغيرة والمتوسطة أما جورجيا فقد أعلنت حكومتها عن حزمة دع تعادل 2 في المائة من الناتج المحلي الإجالي وتشمل تأجيل دفع الاستحقاقات الضريبية على دخل الأفراد والشركات الصغيرة والمتوسطة العاملة في قطاع السياحة حتى نوفمبر 2020، وزيادة نظام ضمان الائتمان، والإنفاق الرأسمالي. كما قرّرت الحكومة أنها ستموّل أي زيادة مطلوبة في الإنفاق الصحي. من ناحية أخرى، قدمت الحكومة الفرنسية حزمة مالية بقيمة 45 مليار يورو (2 في

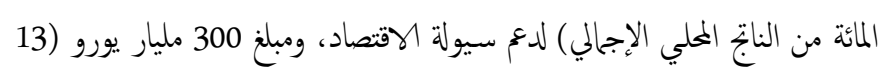
في المائة من الناتج المحلي الإجالي) كضانات للقروض المصرفية الممنوحة للقطاع الخاص، بهدف تبسيط وتعزيز التأمين الصحي للمرضى ومقدي الرعاية لم، وزيادة الإنفاق على الإمدادات الطبية، ودع السيولة من خلال تأجيل مدفوعات الضمان الاجتاعي والضرائب على الشركات، والدع النقدي المباشر للمشاريع الصغيرة والمتوسطة. كذلك أعلنت الحكومة الألمانية عن حزمة إنفاق وتحفيزات ضريبية بقيمة 156 مليار يورو (4.5 في المائة من الناجت المحلي الإجلالي) لدع الرعاية الصحية، وتعزيز البنية التحتية للقطاع الصحي، وتوسيع نطاق استحقاقات رعاية الأطفال للأسر ذوي الدخل المنخفض، كما أعلنت عن 50 مليار دولار لدع أصحاب المثروعات الصغيرة والمتوسطة ( Federal على مستوى أميركا اللاتينية، وأرصدت الأرجنتين نحو 1 في المائة من ناتجها الإجالي ووجهته إلى زيادة الإنفاق على قطاع الصحة، ودع الأسر الفقيرة من خلال التحويلات النقدية المباشرة، وزيادة استحقاقات الضمان الاجتاعي، بالإضافة إلى دع القطاعات المتضرّة من تفشي الفيروس. وفي البرازيل أعلنت السلطات عن دع نقدي مؤقت للأسر الفقيرة، وإعفاءات ضريبية مؤقتة وخطوط ائمان مباشرة للشركات بهدف حاية القوى العاملة لديها، وتحويلات جديدة من الحكومة الاتحادية إلى حكومات الولايات لدئ الإنغاق الصحي. وفي تشيلي قدمت السلطات حزمة من الندابير المالية تصل إل 11.75 مليار دولار أميركي (نو 4.7 في المائة من الناتج المحلي الإجالي) لدئ العهالة وسيولة الشركات الصغيرة والمتوسطة؛ إذ تشمل مجموعة الندابير زيادة الإنفاق على الرعاية الصحية، وتعزيز الإعانات واستحقاقات البطالة، وحزمة من التحفيزات الضريبة. من ناحية أخرى، أنشئت الحكومة الكولومية الصندوق الوطني للطوارئ الذي سيموَّل جزئًا من الصناديق الإقليمة والدولية. وأعلنت الحكومة كذلك عن دع إضافي لميزانية 


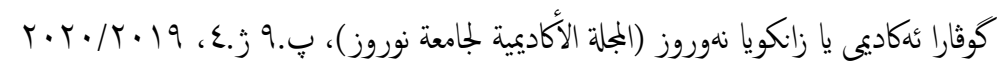

شأها توفير موارد إضافية للمصارف البريطانية بما يمكنها من توجيه الأتمان للقطاع المنزلي (الأفراد والأسر) وقطاع الأعال (الشركات) في المملكة المتحدة خلال مدة تفشّي فيروس كورونا، كما وضع بنك إنجلتزا خطة لمراقبة المصارف حول مدى قدرتها على توظيف هذه الموارد في مصلحة الأفراد والثركات ضد تداعيات الفيروس. (

(Bank of England (2020)

وفي الوقت الذي أعلنت فيه غالبية المصارف المركزية العالمية خفض معدلات فائدتها النقدية، تحفّظ البنك المركزي الأوروبي على الاستجابة لتفّي فيروس كورونا بالنج نفسه الذي اتبعه البنك الاحتياطي الفيدرالي؛ إذ أبقى على معدلات الفائدة دون تغيير في حدود سالب 0.5 في المائة، في حين بلغ سعر فائدة إعادة الشراء صفراً؛ إذ اتِّذ منحى آخر من خلال الاعتماد على عمليات التيسير الكمي مع إبقاء أسعار الفائدة كما هي دون تغيير بضّ أموال من خلال التوسّع في شراء السندات الحكومية وشراء سندات القطاع الخاص بقيمة 120 مليار يورو حتى نهاية عام 2020 مما عزّز من مستوى السيولة المصرفية لدى البنوك الأوروبية. بالإضافة إلى ذلك، قدّم البنك المركزي الأوروبي حزمة من التسهيلات الآتمانية للمصارف الأوروبية مع تشجيع المشروعات الصغيرة والمتوسطة على الاقتراض بأسعار فائدة تيسيرية. وفي السياق نسه عزّز البنك المركزي الأوروبي في 18 مارس 2020 تسهيلاته الأتمانية في مواجهة فيروس كورونا بتقديم 750 مليار يورو عبر برنامج تمويل طارئ أُنْيَّ لهذا الغرض Pandemic Emergency Purchase

(European Central Bank (2020) ').Programme (PEPP) استدرك مجلس الاحتياطي الفيدرالي الأميركي لاحقًا ضرورة تعزيز الخطوة التي اتخذها في مواجحة الفيروس بتخفيض سعر الفائدة بواقع نصف نقطة مئوية من خلال إطلاق برنامج تيسير كي بقيمة 700 مليار دولار من خلال شراء سندات خزانة أميركة في حدود 500 مليار دولار، إضافة إلى أوراق مالية كضان لرهونات عقارية في حدود 200 مليار دولار.كما خفض سعر الفائدة على الائتان الطارئ بواقع 0.25 نقطة مئوية إلى جانب ضحنّ نحو 1.5 تريليون دولار لتعزيز السياسات التحفيزية التي أعلنها مسبقًا.

2.4 الآثار المستقبلية في صعيد السياسات التجارية والاقتصادية قبل الحديث عن الاثار المستقبلية علينا أن نقر بان الآثار الآنية على جوانب اقتصاد العالم بعد انتقال الفيروس التاجي كوفيد-19 أدت إلى خلق حالة من الفوضى
والتشجيع على الاقتراض ومنح مزايا تفضيلية للمقترضين من المصارف الأميركة. (

(IMF $(2020$

في السياق نفسه، بعد يوم واحد فقط من تخفيض مجلس الاحتياطي الفيدرالي الأميركي لسعر الفائدة، أعلن بنك كندا المركزي ( (2020 (Bank of Canada) كذلك تخفيض سعر الفائدة النقدية بواقع 0.5 نقطة مئوية لتعزيز مناعة الاقتصاد

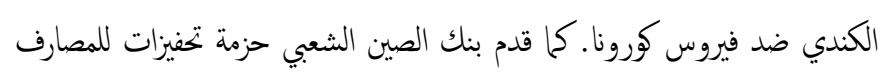
التجارية من خلال تخفيض نسبة الاحتياطي القانوني للمصارف التجارية بما يتزاوح بين 0.5 إلى 1 نقطة مئوية، مما سمح بتوفير ما يعادل 79 مليار دولار لتحفيز الاقتصاد الوطني. كماكان للمصارف المركزية في الدول الاكندنافية دور في حزم التحفيز التي قدمتها غالبية دول العالم؛ إذ خفض بنك النرويج المركزي سعر فائدة السياسة النقدية بنحو نصف نقطة مئوية مما أدّى إلى انخفاض تكليف الإقراض، بالإضافة إلى تقديم تسهيلات ائزانية عاجلة للقطاع المصرفي من أجل ثلاثة أثهر. في حين ضّّ بنك

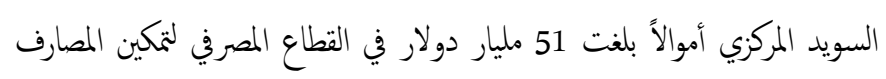
السويدية من تقديم التمويل اللازم للشركات المحلية لتوفير المستلزمات الطبية اللازمة للحدّ من انتشار الفيروس في السياق نفسه، خفض بنك اليابان المركزي من سعر فائدة السياسة النقدية، فيا تدرس الحكومة اليابانية إمكانية تقديم تخفيضات إضافية والمزيد من تحفيز الظروف النقدية. كما لجأ بنك الأرجنتين المركزي إلى تخفيض نسبة الاحتياطي النقدي القانوني على الائتمان المصرفي للأسر الفقيرة، والمشروعات الصغيرة والمتوسطة. كما خفض البنك المركزي البرازيلي سعر الفائدة بعقدار 50 نقطة أساس إلى أدنى مستوى تاريخي وهو 3.75 في المائة. كما أعلن عن حزمة من القروض المدعومة بسندات القطاع الخاصة للمؤسسات المالية، وخضض البنك الاحتياطي الأسترالي سعر الفائدة النقدية مرتين في مارس 2020 بمقار 25 نقطة أساس ليصل إلى 0.25 في المائة، كما أعلن كذلك عن خفض العائد على السندات الحكومية من أجل 3 سنوات بنحو 0.25 بالمائة من خلال شراء سندات حكومية في السوق الثانوية. في السياق نفسه وبالإضافة إلى تخفيض سعر فائدته النقدية بواقع 0.5 في المائة، قدّم بنك إنجلتزا المركزي حزمة من الحوافز لدع قطاع المشروعات الصغيرة والمتوسطة، بالإضافة إلى تخفيض متطلّبات رأس المال للمصارف البريطانية. هذه الإجراءات من 


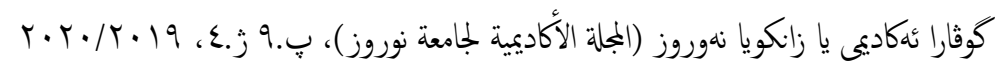

للبيولوجيا والمصدر الرئيس للأجزة الطبية وفقاً لإدارة الأغذية والأدوية FDA في

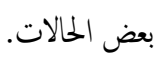
تعدُّ أمريكا مصدر 99 في المئة من الأحذية المبيعة في الخارج، و70 في المئة منها قادمة من الصين. النسبة نشها مع 72 بالمائة من الهواتف الذكية، وشكلت الصين 18 بالمئة من واردات أمريك العام الماضي؛ إذ إن قبل ظهور الازمة في ووهان الصينة صدرت قطع كيرة من مكونات السيارات من ووهان (أنتجت جنرال موتورز ما يقرب من 000،640 سيارة في مقاطعة هوبي، وعاصمتا ووهان ، في

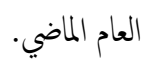
إن الخلاف حول ما يشكل "حاساً" أو "استراتيجياً" هو في تقدم الصين في الحقبة الماضية لكن أمريكا تبنت بالفعل فكرة ضوابط التصدير للحد من بيع تكنولوجيا ومعدات الدفاع الرئيسة، كما فعل معظم حلفائها، فقد يكون تطبيق منطق مماثل على الواردات أكثر صرامة، خاصة وأن أوروبا تقيم الصين بشكل مختلف خصوصا في مسألة شركة هاواي، ولكن هذا لا ينبني أن يعوق أمريكا من البدء في بناء نظام إمداد متعدد الأطراف جديد. وهو المقتح لاستبداله بنظام العولمة؛ إذ إن الشركات التي كانت تخشى ارتفاع نكاليف العحلة سوف تغادر الصين؛ لأن النظام التجاري العالمي بعد انتهاء أزمة كورونا سيتغير العمل به. وقد بدأت ملامح الحرب التجارية بالظهور بين أمريكا والصين أواخر عام 2018، من خلال مراجعات قانون الاستثمر الوارد من خلال لجنة الاستثمر الأجنبي في أمريكا (CFIUS) ومُرِّر مشروع القانون الذي يفرض تلك التغييرات في عام 2018 بدع ساحق من الحزبين الحاكين في أمريكا، ويستمر هذا الدع لإعادة النظر في اعتماد

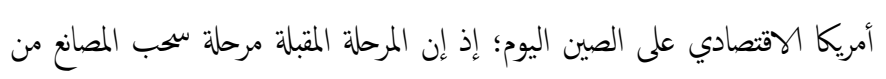
الصين وبدء التصنيع في أمريكا او دولة من دول الحلفاء لها. 2.2.4 الحرب الاقتصادية بين أمريكا والصين يتيين من خلال قراءة الأرقام والمعطيات أن النصيب الأكبر من الثروة يتجه بصورة من الشمال، أي من أمريكا وكبريات العواصم الأوروبية، نخو المجال الآسيوي وخصوصاً الصين، وقد ارتغ اقتصاد الصين من 4\% من الناتج الإجلالي العالمي في عام 2000، أي بقيمة 1.2 تريليون دولار، إلى ما قيمنه 12.3 تريليون دولار سنة 2018، لتشكل نسبتها 15\% من اقتصاد العالم، وبذلك قفزت من المرتبة السادسة

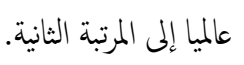

الاقتصادية، وتعدُّ آثار أزمة كورونا شديدة الأثر بحيث بدأت آثارها تظهر خلال حدوث الازمة وسوف تتأثر قطاعات كثيرة بسبب هذه الازمة والتي منها: قطاع السياحة وقطاع الصناعة والتجارة والقطاع المصرفي وقطاع الطاقة، كل هذا التأثير سوف يكون مرتبطا بنتائج الحرب الباردة بين كل من الصين وأمريكا، والتي سنيين ملامح ننائجها من خلال المحورين الآتيبن: 1.2.4 الحرب التجارية بين أمريكا والصين خلال الحرب الباردة، اجتع التحالف الغربي لإنشاء ${ }^{1}$ COCOM، وهي اللجنة التنسيقية للرقابة على الصادرات متعددة الأطراف، وهو نظام تصدير مهدف إلى منع بيع التقنيات العسكرية ذات الاستخدام المزدوج الحساسة وهو تحالف ملتزم بالحد من الواردات والصادرات الاستراتيجية الرئيسة من الصين وإلها. على مدار العامين الماضيين، تغيرت وبجة نظر أمريكا بشأن الصين بمقدار 180 درجة، إن الأمة التي انتشل تحولها مئات الملايين من براثن الفقر وحفزت دعوات جادة لفحص "أنموجج الصين" - حكومة سلطوية متزوجة من الرأسمالية المدارة ينظر إبها الآن معظم القادة السياسيين بوصفها منافسا استراتيجيا في أحسن الأحوال، على أنها عدو خطير في أسوأ الأحوال وبصرف النظر للتحدي العسكري الموثق جيداً منذ اندلاع ووهان، ظهرت التهديدات الاقتصادية والصحية بشكل إذ تعدُّ الصين بأن من حقها أن تمتلك حقوق الملكية الفكرية بعد التعديل على المنتج المبتكر ، وتأخذ حق البيع له استنادا إلى قانون منظمة حقوق الملكية الفكرية العالمية (الوييو) بينا ترى أمريكا بأن ليس من حق أي طرف الاستحواذ على حقوق منتوج

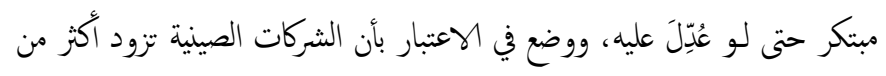
90 في المائة من المضادات الحيوية الأمريكية ، و 70 في المائة من أسيتامينوفين (وهو تايلينول)، ونصف الهيبارين المضاد للتخثر تقريباً. "تسعى أمريكا بشتى الطرائق لجمع المعلومات حول هذا بسبب غوض السوق الصينة وحفظ السجلات التي تهيمن عليها الدولة. تشير بعض الدراسات إلى أن ما يصل إلى 80 في المائة من المكونات

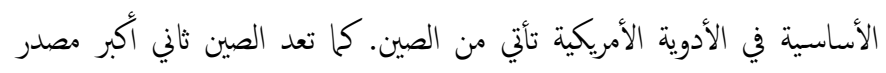

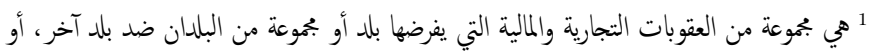

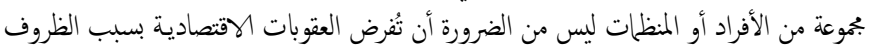

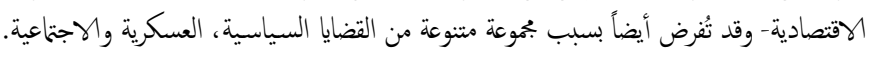
يككن استخدام العقوبات الاقتصادية لتحقيق أغراض محلية ودولية. 


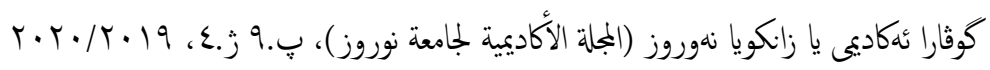

استباقي، والتايل من البيت الأبيض والمنظمين يعني أن هواوي من المربح أن تتمنع بنصر جزئ في الأقل في جهودها للانتشار. ومن وسائل الحرب الاقتصادية أنموذج جديد يحتذى به عند النظر في مشروع قانون شامل لتطليق أمريكا من النفوذ العميق للصين، هو أثموذج CISADA، قانون العقوبات الشاملة على إيران، والمساءلة، وسحب الاستثفارات لعام 2010، إنه أقل من أحكام هذا النطاق الواسع مشروع قانون لعزل إيران، وأكثر من ذلك أنه يمثل نهاً عملياً على السطح يجمع بين جميع أجزاء الحكومة الأمريكية لاستخدام جميع الأدوات المتاحة للعمل بطريقة منسقة ومتسقة ضد عناصر الحكومة الإيرانية التي يعدونها تهديداً لأمريكا وحلفائها. وهناك مشروع قانون آخر مثل CAATSA، قانون مكافة خصوم أمريكا من خلال العقوبات؛ وآخر هو CAAA قانون مكافحة الفصل العنصري الشامل.كل هذه القوانين ليس الهدف منها الإعلان عن حرب اقتصادية مباشرة؛ بل الهدف منها هو نهج خالٍ من الثغرات ومتسق واسع النطاق. كل هذه أدوات اقتصادية في الحرب الاقتصادية ضد الصين وحلفاهيا. (thedispatch.com) وتثثل الصين تحدياً معقداً وتستحق دراسة جادة في أنها قد بدأت تظهر كقطب موازٍ لأمريكا في العالم؛ إذ أثبتت الصين أنها أكثر من كذا مرة بأهها قادرة على التحايل على سنوات من الجهود الأمريكية لاحتواء التهديد الأمني أو معالجة انتقائية للممارسات التجارية غير العادلة، لذا فان الحرب الاقتصادية بين اطراف النزاع سوف تنتج بعالم

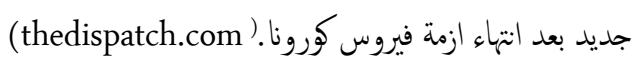

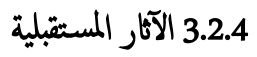

\subsubsection{4 التنافسية الحادة من بعد التعددية القطبية}

من المؤكد كورونا أصبح واقعاً دولياً، هو أصلاً بصدد التشكل، إذ تبلورت الكثير من ملامحه وشخوصه خلال العشريتين الأخيرتين في الأقل، عني بذلك رسوخ حالة التعدية القطبية، وأن كل ما سيفعله الكوفيد 19 لا يزيد على تعميق واقع هذه

النعددية القطبية، مع إعطاء مزيد من الفرص لصعود الصين وتراجع أمريكا. بيد أن ذلك لا يعني بالضرورة أن الصين ستحل آلياً محل أمريكا، بل الأربح أن تظل أمريكا تتصدر الريادة العالمية لعقود قادمة من الزمن، بالنظر إلى مستوى انتشارها العسكري في المضايق والبحار واليابسة، وامتداد قواعدها العسكرية الضخمة، وتقدم جامعاتها ومراكز بحوثها مقارنة بالدول المنافسة، واعتماد الدولار عملة
تجاوز الناتج الإجلالي المحلي للصين 6.5 تريليون دولار أمريكي في النصف الأول من سنة 2019. ونما اقتصادها بنسبة 6.2\% في الربع الثاني 2019 مقارنة بـ6.4\% في الربع الأول من العام نفسه على أساس سنوي، بينا نما بنسبة 6.3\% في النصف الأول من 2019. وتعدُّ الصين أكبر مستورد للنفط الخام في العالم بنحو 10 ملايين برميل يومياً، وثاني أكبر مستهاك له بواقع 12.5 مليون برميل يوميا، أي بنسبة 14\% من خجم الطلب العالمي على النفط يومياً، وثاني أكبر اقتصاد في العالم بعد أمريكا. ووفقاً للتقديرات، فإن اقتصاد الصين سيتفوق على نظيره الأمريكي من حيث حصته من الناتج المحلي الإجلالي، بحلول عام 2029 بقيمة ناتج محلي تبلغ 25.6 تريليون دولار ، مقابل 24.5 تريليون دولار للولايات المتحدة. (Farid Zakaria 2011) كل هذه القضايا أصبحت محاور حرب اقتصادية بين الأطراف والذي عملت أمريكا على تغر تشريعاتها تجاه الصين بخلق نظام جديد للشفافية الأمريكية في التصنيع وسلسلة التوريد الذي قدمه سين توم كتون اند ريب ومايك غالاغر، بالإضافة إلى تشريع مماثل من السناتور. جوش هاولي، وهناك تشريع للتحقيق في التستّر على الفيروسات التاجية في الصين (أيضاً هاولي والنائبة إليز ستيفانيك)، قانون المراجعة الاقتصادية والأمنية بين أمريكا والصين (السيناتور كريس كونز، النائب براد شيرمان)، وبحر الصين الجنوبي وفرض عقوبات بحر الصين الشرقي قانون عام 2019، قانون إنفاذ التجارة العادلة مع الصين، وفواتير التعامل مع عمليات التأثير الصينية، وهو مشروع قانون يمنع المستتمرين الصينيين من الوصول إلى صناديق ترويج الأعمال التجارية الصغيرة الأمريكة، وفواتير تتعلق بالاتصالات الصينية وعملاق التجسس هواوي، الصادرات الصينية إلى أمريكا ومئات أخرى. (thedispatch.com) كل هذه التشريعات والقوانين هي وسيلة للضغط على الصين بشكل خاص، وعلى حلفاء أمريكا والموردين الأمريكيين للابتعاد من الصين، وعدم الاستفادة من العلاقات المالية الحالية مع الصين، وحالة هواوي خير دليل على ذلك؛ إذ أدى فشل أمريكا في التصرف بسرعة كافية على G و والاستغلال الصيني لهذه الأخيرة لترسيخ

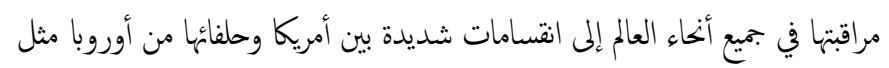
ألمانيا والمملكة المتحدة وكذلك أن الحكومة الأمريكية لا تزال تمنح استثناءات لحظر Huawei الشامل، هذا الافتقار إلى الانساق، والفشل في التصرف بشكل 


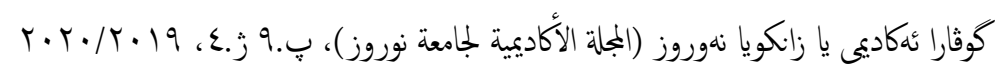

حديثه عن طبيعة النظام الرأسلالي: "كل ما هو صلب يتبخر في الهواء، وكل ما هو

مقدس يتحول إلى علماني مدنس" (2016، The Communist Manifesto) ما هو مؤكد هنا أن دخول أمريكا في صراع استرانيجي حاد مع الصين من شأنه أن يلحق ضرراً بالغاً بمستوى العيش والرفاه الأمريكين، بحكم أن اقتصادها بات يعتمد إلى حد كير على شبكات التزود من الصين وصناعها الضخمة التي لا يككن الاستغناء عها، وقد بينت جائحة كورونا نسها حاجة أمريكا إلى الصين في مجال التجهيزات الصحية والأدوات الواقية البسيطة وغيرها. Foreign (2020، (Affairs وإن كان من الواضح إلى حد الآن، وجود محاولات مستمرة لتطويق الصين في البحر الجنوبي وما بعده، عبر انتشار عسكري واسع النطاق في المحيطين الهندي والهادي مع تسليح تايوان واليابان ووكريا الجنوبية. وقد سبق لأوباما أن دشّن سياسة الانسحاب من الشرق الأوسط، بغرض التفرغ لموابهة الخطر الصيني، لتدارك ما يعدُّه أخطاء استراتيجية وقع فيها بوش الابن، وبموازاة ذلك تسعى أمريكا إلى إحداث توازن مع الصين من خلال دع الهند عسكرياً واقتصادياً باتجاه أن نكون "مصنعاً" أرخص، وأكثر تنافسية من الصين. مقابل ذلك تعمل الصين من جهتها على تطويق هذا الطوق من خلال توسيع انتشارها العسكري في بحر الصين الجنوبي، وبناء الموانئ وعقد الاتفاقيات التجارية مع

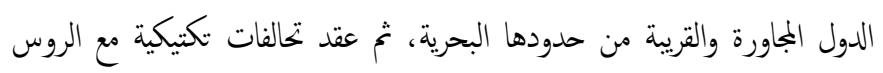
والباكستانيين والإيرانيين ومحاولة تجميد مناطق الصراع وبؤر التوتر ما أمكن.

- 2.3.2.4 ضعف العولمة وتآكلها وبجت جائحة كورونا ضربة قوية للعولمة، التي تعاني أصلاً كدمات سابقة وبهها لها تزامب بسبب حروبه التجارية وإجراءات المحاية التي فرضها على الدول. نخ نعيش عصراً معولماً بأتمّ معنى الكلمة إذ تترابط مختلف قارات العالم عبر شبكة معقدة من المعاملات المالية والسلعية والبورصات والأسواق والشركات والاتصال اللوجستي الرقي، وعليه فإن أي هزة تقع في أي بلد من البلدان، إلا وتكون لها ارتدادات واضحة في مختلف الأسواق العالمية. العولمة نسها تواجه صعوبات كبيرة قبل كورونا، ومن ذلك الحرب التجارية وإجراءات المماية التي فرضها ترامب على الصين، بل فرضها على دول تصنف في دائزة الحليفة مثل كندا ودول الاتحاد الأوربي والمكسيك وغيرها.
رئيسة في تبادل الطاقة والتجارة العالمية في إطار ما يعرف بنظام برنتن، بيد إنها ستلقى منافسة جادة من الصين، وبدرجة أقل من الروس وقوى أخرى صاعدة، مثل الهند والبرازيل وغيرها. أمريكا نهت نفسها بكثة الحروب والتدخلات العسكرية النشطة. من حرب الخليج سنة 1990 إلى حرب يوغسلافيا سابقاً سنة 1999 ثم أفغانستان سنة 2001 المى حرب العراق سنة 2003، وأخيراً التدخلات الجزئية في سوريا والعراق مجدداً، إلى الانتشار جنوب الصحراء عبر ذراع الافريكوم وغيره. ( رفيق عبد السلام، (2008 إن المفارقة العجية هنا، إذا استخدمنا مصطلح هيجل مكر التاريخ، فإن السنوات التي أعلنت فهيا القوة الأمريكية تفوقها الكامل ودخول الأحادية القطبية من دون منازع، هي نفسها المدة التي بدأت تتشكل فيها معالم التعددية القطبية. وفي الوقت الذي كانت أمريكا تغرق في حروب استنزاف عبثية في الشرق الأوسط، الذي لم يكن بمثل خطراً جادا من الناحية العسكرية، كان الصينيون منهوكن في تطوير اقتصادهم وقدراتهم التسليحية وتوسيع حضورهم التجاري العالمي في إفريقيا وآسيا وختتلف قارات العالم. ( 2011، Edward N. Luttwak ) استفادت الصين من سياسة الانقتاح الخارجي التي دشنها الزعيم، دينغ شياو بنغ منذ نهاية السبعينيات بعد عقود طويلة من العزلة، وقد سعت ضمن سياسة الانقتاح هذه إلى اكتساب الخبرة التكنولوجية الغربية وحسن إدارة اقتصاد السوق والانقتاح على العالم الخارجي. كل ذلك كان ومازال يجري تحت عنوان اشتراكية بخصائص صينة: وهي في الحقيقية رأسمالية بخصائص صينية. بل أهم من ذلك أن الصين نجحت إلى حد كير في توجيه مسار العولمة لصالحها بعدما تحولت إلى مصنع كير للعالم، إلى الحد الذي بات من الصعب الاستغناء عن الأسواق الصينية وصناعتها الكبيرة في إطار ما بات يعرف بسلاسل التزود Chaines supply. كانت هناك حسابات وتكتيكات متناقضة بين الغرب والصين. كان الغرب يراهن على احتواء الصين والاستفادة من ضخامة سوقها عبر التخفيف من صلابتها الأيديولوجية، وإدماجحا تدريجياً في النظام الرأسلالي العالمي، وكان الغرب مسلحاً هنا بخرته السابقة في النعامل مع المنظومة الشيوعية في الاتحاد السوفياتي، ونظريات العلوم الاجتاعية والسياسية بكتيتها التاريخية، التي تبشر بأن النظام الشيوعي لن يصمد كثيراً أمام منطق الرأسلالية الكاسح، على وفق مقولة ماركس في البيان الشيوعي في معرض 


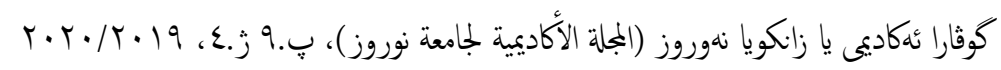

الأمثل، ولكن تبين أن الهويات الدينة والقومية والصراعات العمودية لن تختني اليوم أو غداً، بل شهد عصر العولمة أكثر الصراعات الاثنية والدينية دموية.

\subsubsection{4 شراكة الاتحاد الأوريي المتهاوية}

إننا سنكون إزاء أوروبا أكثر قلقًا وأقل اندماجاً، فأوروبا مشحونة بالأزمات الاقتصادية والنزعات الشعبوية والانعزالية، وسيتغذى ذلك أكثر بالأزمات الاقتصادية.

سوف تكون دول الضفة الجنوبية للاتحاد وفي مقدمة ذلك ايطاليا واسبانيا والى حد ما فرنسا، ستخرج منهوكة من هذه الأزمة أكثر من غيرها، وهي التي تعاني أصلاً مخلفات الأزمة الاقتصادية لسنة 2008، ولا يستبعد أن تتجه دول مثل ايطاليا واسبانيا واليونان إلى الانسحاب من الاتحاد، رداً على ما تعدُه تجاهل بروكسيل وأنانية ألمانيا الثرية والقوية، إذ المؤكد هنا سنشهد صعود النزعات القومية وغلبة March الاعتبارات الوطنية المحلية على حساب الاعتبارات الأوروبية الأوسع 2020 , Politico الأقل توحداً، وهذا له آثار على الناتو والتجارة وخير دليل هو اجتماع مالية الاتحاد الأوربي بشأن حزمة مساعدات بقيمة 500 مليار يورو و1000 مليار تأسيس صندوق لإعادة الاعمار، ولكن لم يحصل توافق نهائي وكان أساس الخلاف حول "سندات كورونا" ويتزكز الخلاف بين دول شمال أوروبا المحافظة ماليا مثل ألمانيا وهولندا، ودول الجنوب الأشد تضرراً من أزمة كورونا مثل إيطاليا وإسبانيا، بشأن إمكانية إصدار سندات مشتركة لدول الاتحاد تعرف باسم "سندات اليورو" لمساعدة الدول الأشد تضرراً في الاقتراض من الأسواق المالية بتكلفة محتملة، وهو ما ترفضه بشدة دول مثل ألمانيا وهولندا والنمسا.

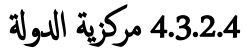

الأربح أننا في السنوات القادمة سنشهد مزيدا من التوجه نخو المركزية للدولة في مقابل ما عرف في نظرية الليبراليين الأمريكان بالحد الأدنى من الدولة (2018،

.(Robert Nozick

المؤكد أن الدولة ستضطر إلى الرجوع لبعض المساحات التي انسحت منها بتخطيط وتدبير مسبق لصالخ الشركات الخاصة في أجواء النيوليرالية، وهذا الأمر ليس جديداً، ففي أجواء الأزمة الاقتصادية لسنة 2008 تدخلت الدولة بقوة لضخ الأموال وفرض القيود على البنوك التي شارفت على الانهار، وجرت معها الوضع
ومن سخرية الأقدار أن البلد الذي كان يبشر بفضائل العولمة ويعمل على توسيع شبكاتها، هو أول من يبادر بخوض المعركة ضدها، ولا يتردد في خرق قوانينها، تزامب وفريقه اليميني يرى العولمة في صورتها الراهنة، تعبيراً عن تهاون الليبراليين، وعلامة على سذاجته السياسية في التعامل مع إدارة الوضع الدولي منذ كلينتون وانتهاء بأوباما. وهكذا وضع تزامب على عاتقه وقف هذا المسار، وإن اقتضى الأمر ضرب اتفاقيات النجارة الحرة، ومجمل الالتزامات الدولية عرض الحائط، ما دامت America تتعارض مع المصلحة الأمريكية العليا، وذلك تحت شعار أمريكا أولا (Globalization and Its Discontents Revisited ،2017) .First الواضح اليوم أن كورونا تخولت من فيروس بيولوجي قاتل إلى فيروس سياسي اقتصادي لا يقل فنكاً، وقد اضطرّت الدول المتقدّمة إلى فرض الحجر الصحي وعزل المدن وإغلاق الحدود، وايقاف الرحلات الجوية والبحرية، مع ما تبع ذلك من تعطل الأسواق والمعاملات المالية والبنكية وتدفق البضائع وحركة البشر. (2020، trump-protectionism-nationalism-globalization-killing(coronavirus العولمة ستظل موجودة معنا إلى وقت طويل؛ لأن تطور وسائل النقل وتقنيات التواصل الحديثة وتداخل المصاح بين الشعوب والدول يفرض ذلك بالضرورة، ولكنها ستظل موضع صراع وتجاذب حول من يتحكم في وجتها ومن يستفيد أكثر من ثمارها؟ ولذلك الأربح أن تسير العولمة في خطين مترابطين، خط يدفع باتجاه الانقتاح والتواصل والإقرار بالتعددية الثقافية والعرقية، وآخر يدفع باتجاه الانغلاق والتعصب وصراعات الهوية. لكن العولمة في صورتها الأمريكية ليست مساراً حتمياً وتصاعدياً على طريقة القصص الرومانسية السعيدة، بل شأها في ذلك شأن الظواهر السياسية والاجتاعية الكبرى قابلة للارتداد والتقدم والتراجع. ظلت العولمة مسكونة منذ نشأتها بضرب من التناقض الداخلي، بين خط عولمة الأسواق والبضائع العابرة للحدود والثقافات، وبين صعود مطالب الهويات الدينية والقومية والنزعات الإثنية وحتى القبلية الضيقة وغيرها. تصور الليبراليون الجدد إن ذلك مجرد حالة عارضة لن تصمد كثيرا أمام الصوت الباطني للنارين الذي يدفع نحو ليبرالية السياسة والاقتصاد باتجاه الأثموج الأمريكي 


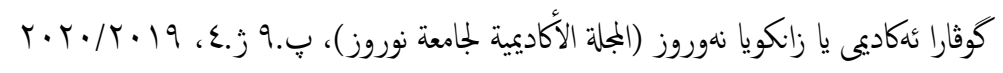

طبعاً هذا الأمر لا يعود إلى قلة إمكنيات أو قلة موارد، بل نتيجة خيارات سياسية واقتصادية غير متكفئة تعطي الأولوية القصوى لصناعة السلاح وكبى الشركات

$$
\text { على حساب رفاه المواطن وصحته العامة. }
$$

نظام السوق ههدف إلى الريح بدرجة أولى، وقد أثر ذلك فعلاً في التطور غير المنكلفئ حتى داخل صناعة الأدوية واللقاحات نفسها، قبل أن نتحدث هنا عن أسبقية صناعة السلاح أو النفط مثلاً الاستثار الرأسالي يركز في الأدوية واللقاحات الأكثر استخداماً وذات العائد الملالي السريع. ولم يكن يخطر ببال شركات الأدوية واللقاحات مثلاً أن يجتاح العالم وباء خاطف سريع الاتتشار ، ولذلك اتجهت العناية إلى صناعة أدوية ولقاحات كان يبدو أنها ستكون أكثر طلباً وربجية، وهذا الأمر يبين تهافت تلك المقولة التي يبشر بها الليبراليون والتي مفادها أن مصلحة الأفراد تؤول في نهاية المطاف إلى مصلحة المجموع. إذ الواقع يبرز أن مصلحة جنرال موتورز أو جنرال إلكتريك ليست بالضرورة مصلحة عموم الأمريكيين، قبل أن نحدث عن مصلحة العالم. ( أنتوني نيونشتاين, تربمة أحمد عبد المميد، 2019) بيّنت جائحة كورونا الطابع الاستراتيجي لقطاع الصحة، ولذلك اضطرت الدول إلى ضخّ الأموال على عجل لبناء وتجهيز المستشفيات، بل سُخِّرت الجيوش وختلف أبحزة الدولة لمعاضدة القطاع الصحي العموي. وقد كان أداء الدول الغربية نفسها متفاوتاً على هذا الصعيد، فبينا أظهرت ألمانيا والبلان الإسكندافية وتركيا جاهزية قوية في موابحة الجائحة بدت أمريكا وبريطانيا ودول جنوب أوروبا مرتبكة ومتخبطة.

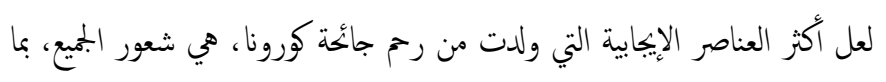
ذلك الحكومات اليمينية وسائر الأحزاب، أصبح القطاع الصحي قطاعاً استراتيجياً، ولا يككن العبث بحياة المواطنين وصهته لصاح رهانات الريح الرأسلالي، ومن المؤكد أنه سيكون من تبعات ذلك عودة الدولة مجدداً إلى مجالات تمدد فيها القطاع

3.4 الآثار البعيدة المدى لـ COVID-19 ( 2020، Robert 'Bob' Maginnis

- كانت أمريكا والصين وروسيا تتنافس بالفعل على النفوذ عبر العالم الناي. هذا

الوباء له تشعبات جيوسياسية أكبر على المدى البعيد للتجارة والوصول

$$
\text { والأمن عبر الأميركتين وأفريقيا والكثير من وسط وجنوب آسيا. }
$$

الاقتصادي كله للندحرج. وهذا الأمر يتناقض في الصميم مع أساس النظام الليرالي القائم على اشتغال السوق على وفق آلياته الناتية ومن دون تدخل الدولة، في إطار ما أسماه آدم سميث باليد الخفية للسوق. (1986، John Gray ) الحتيقة أن الدولة لم تغب أصلاً حتى يقال إنها عادت، ولكن الأصح أنها بصدد إعادة

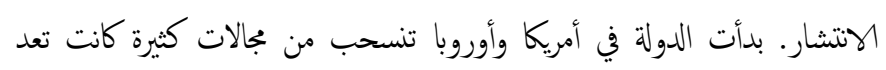
اختصاصاً حصرياً لها، في النعليم والصحة وحتى في مجال الأمن والسجون والرعاية الاجتاعية وغيرها على أساس أن ما يسمى بالتدبير الحر من طرف المؤسسات الخاصة أقل كلفة وأكثر نجاعة. مقابل ذلك امتدت الأعين البصيرة والأيدي الطويلة للدولة في مختلف مناحي النسيج البمتمعي التي ظلت تتوسع أكثر مع تطور تقنيات الرقابة والرصد الإلكتروني وطرائق النعرّف الى الوجه والبصمة. ومنذ أحداث 11 من سبتمبر تعقّدت أكثر آليات الرقابة والتجسس على المواطنين وأطلقت أيدي الأجزة الاستخباراتية والأمنية دون حسيب أو رقيب باسم مقاومة الخطر الإرهابي. وخلال اتساع جائحة كورونا استخدمت الصين ما يعرف بقاعدة البيانات

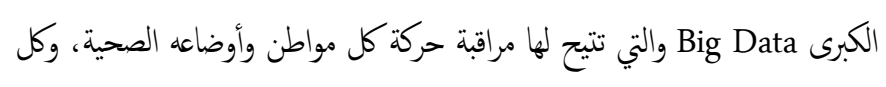
معاملاته المالية والإدارية. كما أن الإدارة الأمريكية لم تتردد في طلب الشركات الأمريكية المتخصصة، تزويدها بقاعدة بيانات المواطنين بغرض ضبط مواقع مستخدي الهواتف النقالة والأجزة الاككتونية ومجال حركنه، ومدى التزامم بالحجر الصحي، ومن بين هذه الشركات Uber, Twitter, Google Facebook و ABM و Apple، أصبح ما يعرف بالذكاء الاصطناعي بمثابة عين وبصر الدولة الذي لا ينام ويحصي أدق دقائق الأمور ، يضاف إلى ذلك استدعاء الجيوش والأبهزة الأمنية في أغلب دول العالم، بما في ذلك الديمقراطيات العريقة، سواء لفرض العزل في البيوت أو في إسناد الطوام الصحية وبناء المستشفيات والمراكز الصحية. والدولة تقوم بهذه الإجراءات؛ لأن مصلحة الناس وحاية الحياة تقتضي ذلك.

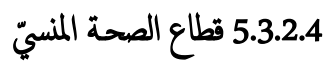

كثفت أزمة كورونا الوجه المخيف لأمريكا، ومن ذلك هشاثة منظومتها الصحية ويجز مستشفياتها عن توفير الحد الأدنى من التجهيزات الصحية، بما في ذلك أدوات الوقاية للطوام الصحية من أطباء وممرضين. إنه لمثهد سريالي أن يشاهد العالم بعض

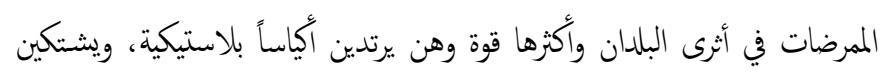
من عدم وجود بدلات صحية وأدوات واقية من الفيروس. 


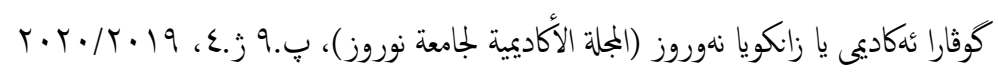

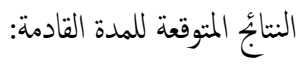

جمم الاقتصادي العالمي هو 85 ترليون دولار منه 20 نرليونا لأمريكا ولكن حجم الدين العالمي هو 250 أي ان الدين العام العالمي يشكل ثلاثة اضعاف الناتج القومي مما ستدل على حجم ازمة الكساد المرتقبة.

ستعاني أمريكا مخلفات اقتصادية ثقيلة الوطأة في مرحلة ما بعد كرونا ولن تتجاوزها في سنوات قليلة، وقد صار مألوفاً جداً أن يتحدث الخبراء عن أزمة أشد ضراوة من أزمة 1929 التي ضربت الاقتصاد الأمريكي وبقيت تداعياتها قائمة على امتداد ثلاثينيات القرن الماضي. خلال أسبوعين فقط من بداية الأزمة خسرت أمريكا عشرة ملايين وظيفة، ومنذ الأسابيع الأولى خسر الاقتصاد الأمريكي مع ما يربو على 800 مليار دولار، وصناعة السفر والفنادق وحدها خسرت 355 مليار دولار، ويأتي ذلك وسط أجواء من الاستقطاب الداخلي يعكس انتساماً مجتمعياً حاداً عمل ترامب وفريقه اليميني على دفعه إلى الحد الأقصى. كل ذلك يعني أن الصين ستتقدم على صعيد التنافسية الاقتصادية أكثر ، مع تعزيز حضورها الدولي وسيكون ذلك بكل تأكيد على حساب موق أمريكا في

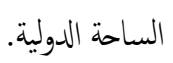
الأزمة الاقتصادية الحالية سوف تؤدي الى حرب اقتصادية وبالوقت نفسه ريما الى حرب عسكرية محدودة على نطاق محدود للغاية الهدف الأساسي منها هو بحر الصين الجنوبي.

المؤكد أن مرحلة ما بعد كورونا سترسخ أكثر واقع التنافسية الدولية وتقلب

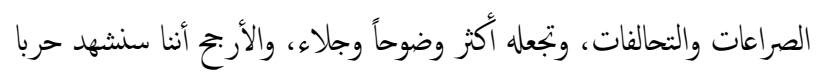
باردة وساخنة في السنوات القادمة في مختلف الساحات العلمية، كما أن التقارب الروسي الصيني، على الرغز من التنافس القائم بينها، من شأنه أن يكبح القوة الأمريكية ويضعف من مكانتها الدولية المتراجعة أصلاً. من خلال تتبع الحرب الباردة بين الصين وأمريكا وجدنا أن هناك اتهامات موجهة للصين بالسيطرة على وكلات الأم المتحدة، وتمند إلى ما وراء منظمة
من المرجح أن يخرج الحلفاء الأوروبيون من الوباء الأقل توحداً ، وهذا له آثار في الناتو والتجارة وخير دليل هو اجتماع مالية الاتحاد الأوربي بشأن حزمة مساعدات بتمة 500 مليار يوره و 1000 مليار تأسيس صندوق لإعادة الاعحار ولكن لم يحصل توافق نهائي وكان أساس الخلاف حول "سندات كورونا" ويتركز الخلاف بين دول شهال أوروبا المحافظة مالياً مثل ألمانيا وهولندا، ودول الجنوب الأشد تضرراً من أزمة كورونا مثل إيطاليا وإسبانيا، بشأن إمكانية إصدار سندات مشتركة لدول الاتحاد تعرف باسم "سندات اليورو" لمساعدة الدول الأشد تضرراً في الاقتراض من الأسواق المالية بتكلةة محتملة، وهو ما ترفضه بشدة دول مثل ألمانيا وهولندا والنمسا. - ضعف الوحدة العالمية "إنهيار في مضمون العولمة" ستسعى المزيد من الدول إلى الاعتماد على القواعد الصناعية المساندة القادرة على توفير القدرات. تدفع حرب النعريفة الجارية بين أمريكا والصين بالفعل العديد من الثركات إلى إعادة التفكير في نهجها تجاه سلاسل التوريد العالمية وتقوم الحكومات بإعادة تقييم اعتادها على المنتجات والمكونات الصينية. - ستزداد التوترات الأمنية إستناداً إلى التقارير الأمريكية الجديدة التي تتهم الصين بعدم الامتثال لمعاهدة الحظر الشامل للتجارب النووية لعام 1996، وقد ينشئ الكونغرس صندوقاً إضافياً لموابحة الإجراءات الصينية في المحيط الهادئ. - الآثار الاقتصادية خطيرة ولا شك في أن تأثيرات COVID-19 عمة بشكل خاص ومضاعفة من خلال ديون أمريكا البالغة 23 تريليون دولار وهذا قد يؤدي إلى أزمة مالية عالمية وانهيار الخدمات المصرفية وانهيار الخدمات المصرفية على الصعيد الوطني في أمريكا بشكل كير مماكان عليه في عام 2008. - - عدم الاستقرار المتزايد ريما يؤدي إلى حرب أخرى؟ نحن نعلم أن مصادفة جائحة إنفلونزا عام 1918 والحرب العالمية الأولى لم تتسبب في الحرب العالمية الثانية، ومع ذلك، فإن مجموعة من العوامل المحيطة بتلك الأحداث شاركت بشكل كير في هذه النتيجة. 5. النتاجُ والتوصيات 1.5 


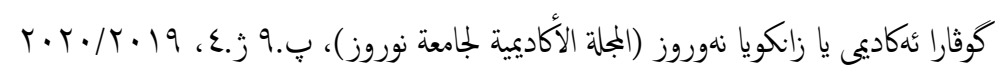

أمريك هذه السنة، كما انتزت السبق في مجال التواصل الرقي من الجيل

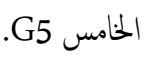

بعد حدوث الاتفف المفتر الذي عقد بين الصين وأمريكا على إدارة العالم نهاية 2020 سوف تظهر بحجم كير استخدامات تقنية الذكاء الصناعي في إدارة العالم وخصوصاً شبكة G5 التي يتنافس عليها الأمريكان والصينيون بشكل شرس بغية الانتشار بها عالمياً وبناء أبرابجا؛ لأن من يتحكم بهذه

$$
\text { الشبكة هو من سوف يحكم العالم في القريب المقبل. }
$$

\section{5 التوصيات}

إن تحليل الأحداث والقطاعات الاقتصادية التي تأثّرت جراء تفثّي فيروس كورونا. وعلى خلاف الصدمات الأخرى وعلى مرّ الزمن كانت تؤُّر في أحد جانبي الاقتصاد الكلي (العرض أو الطلب)، تبيّن أن فيروس كورونا قد أثّر بصورة مباشرة في جانبي الطلب والعرض معاً. لذلك ضرورة العمل بالتوصيات:

الاستجابة السريعة والواسعة على صعيد السياسات النقدية والمالية لدئ الطلب وتوفير التمويل اللازم للقطاعات الختلفة والأكثر تضرّراً من تفشي فيروس كورونا من خلال ضخ سيولة بقيمة تريليون دولارٍ، عبر "الاستخدام الواسع لحقوق السحب الخاصة الحالية في صندوق النقد الدولي" وإضافة خصص جديد يتجاوز خصصات 2009 التي أجريت لتخفيف الأزمة المالية العالمية. تعزيز الإففاق على قطاع الصحة، ورعاية المرضى الذي يتطلب توفير 500 مليار دولار لتمويل خطة كبرى للتعافي الصحي، تمول من وعود المساعدات الإنمائية الرسمية التي وعد بها شركاء التنمية والتي لم تقدم حتى الآن، والحدّ من

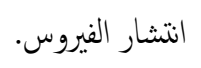

تحفيز حزم الدع المالي من خلال البنوك المركزية أو من خلال إنشاء صندوق تمويلي وحسابات خاصة أُنشئت خصيصاً لهذا الغرض بمشاركة مجموعة من البنوك التجارية.

العمل على خفض أسعار الفائدة النقدية التي أعنتها المصارف المركزية ومؤسسات النقد، بالإضافة إلى تقليل نسبة الاحتياطي النقدي القانوني بما
الصحة العالمية إلى منظمة الطيران المدني الدولي (ICAO) ، وكذلك منظمة

المؤكد هنا أن عالم ما بعد كورونا سيكون أكثر انغلاقاً وحاية وأقل اقتاحاً، ولكن هذا لا يعني انه سيكون خارج نطاق حركة العولمة بإطلاق، الأربح أننا نحن نسير باتجاه عولمة أكثر تنافسية وتعددية ستكون الصين إحدى محركانها الرئيسة، ولن تكون فيها أمريكا إلا لاعباً من بين لاعبين آخرين لا غير. إن مسار العولمة سوف يضعف مع نهاية كوفيد 19، ولكنها ربما تأخذ وبحة مغايرة، غير التي أعدّت في إدارة كلنتون. وكان من المنتظر أن تكون هذه العولمة جسراً لامتداد الشركات والمؤسسات الأمريكية وتوسع اذرعها المالية والتقنية في مختلف أطراف المعمورة، فإذا بها تصبح حركة هجرة للشركات والرأسال الأمريكي نحو الخارج، وكانت الصين أول المستفيدين من ذلك. الصين ترفض الجلوس على طاولة المفاوضات مع أمريكا من أجل بحث صياغة نظام عالمي جديد؛ لأن الصين تقدمت تكنولوجيا وأمريكا تضغط للجلوس معها من أجل قيادة العالم المشتركة بحسب رؤية مراكز الدراسات الامريكية، ومن أهم ملفات الثفاوض بينهم (الدولار أهميته وهيمنته، الثغير المناخي، إدارة الأنترنت، كيفية إدارة شؤون العالم للتجارة). عام 2020 سيفرض الصدام فيه الجلوس على طاولة المفاوضات ينتج عنه اتفاق قطبين هها الصين وروسيا من جهة وأمريكا وحلفؤها من جهة اخرى. إن الصين بدأت تكتسب ثقة ثقافية متزايدة في نفسا وفي دورها العالمي؛ إذ تبدو النخبة الصينية اليوم أكثر اقتناعاً بالدور العالمي للصين، وهي تسير بخُّا حثيثة نحو تربمة هذا التوجه عبر مشروع طريق الحزام الذي يربط الصين بمختلف قارات العالم، ويتيح لها التزود بالطاقة وفتح الأسواق وتصدير البضائع؛ إذ إن الرؤية الصينية واضحة هنا وتقوم على مراحل متدرجة: بناء الداخل الصيني أولاً من خلال الارتفاع بقدراتها العسكرية والاقتصادية، ثخ حاية حدودها ومصالحها في بحر الصين وجنوب شرق آسيا، ثم التمدد خارجياً عبر التجارة والاستثمار في البنية التحتية والصناعة وغيرها. بل إن الصين أضحت تنافس أمريكا جداً في مجال الابتكار العلمي؛ إذ لأول مرة تتقدم على 


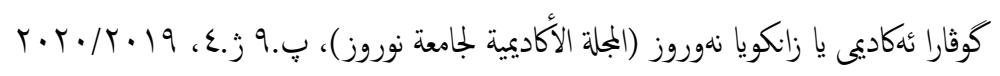

4. OECD (2020), "OECD Interim Economic Assessment Coronavirus: The world economy at risk", March 2020.

5. OECD (2020), "Coronavirus: The world economy at risk", OECD Interim Economic Assessment ,March.

2. WTO (2020), "New WTO indicator finds services trade weakening into second half of 2019", Services Trade Barometer, Sep 2019.

3. World Economic Forum (2020), The Travel \& Tourism Competitiveness Report, 2019.

4. WTO (2020), "WTO DG welcomes G7 leaders' statement on COVID-19”, March 2020. Available at: https://www.wto.org/english/news_e/news20_e/dgra_17mar20_e. htm

5. OPEC (2020), Monthly Oil Report, March 2020.

6. ILO (2020), "How will COVID-19 affect the world of work", March.

7. IMF (2020), "IMF Makes Available $\$ 50$ Billion to Help Address Coronavirus", March 2020. Available at:

a. https://www.imf.org/en/News/Articles/2020/03/04/sp030420-imfmakes-available-50-billion-to-help-address-coronavirus.

8. World Bank (2020), "World Bank Group Increases COVID-19 Response to \$14 Billion To Help Sustain Economies, Protect Jobs”, Available at:

a. https://www.worldbank.org/en/news/press-

release/2020/03/17/world-bank-group-increases-covid-19-responseto-14-billion-to-help-sustain-economies-protect-jobs.

9. ISDB (2020), "IsDB Group's Statement on Coronavirus", March 2020. Available at: https://www.isdb.org/news/isdb-groupsstatement-on-coronavirus.

10. https://g20.org/ar/about/Pages/Previous.aspx.

11. https://g20.org/ar/g20/Pages/documents.aspx.

12. IMF (2020), "Policy Responses". Available at: https://www.imf.org/en/Topics/imf-and-covid19/Policy-Responsesto-COVID-19

13. Federal Reserve System (2020). Available at

14. https://www.federalreserve.gov/newsevents/pressreleases.htm

15. IMF (2020). Available at: https://www.imf.org/en/Topics/imf-andcovid19/Policy-Responses-to-COVID-

16. Bank of Canada (2020). Available at: https://www.canada.ca/en/public-health/services/diseases/2019novel-coronavirus-infection/being-prepared.html

17. Government of the UK, Bank of England (2020). Available at: https://www.bankofengland.co.uk/news/2020/march/the-covidcorporate-financing-facility

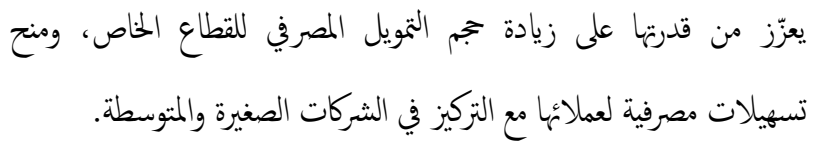

1. IMF, (2020). "World Economic Outlook: Tentative Stabilization, Sluggish Recovery?”, Jan.

2. World Bank, (2020). "Global Economic Prospects: Slow Growth and Policy Challenges", Jan.

3. UN, (2020). "World Economic Situation and Prospects 2020", Jan. 


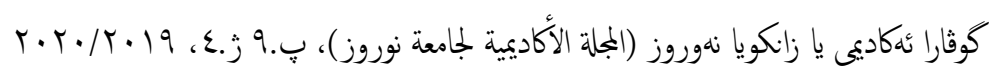

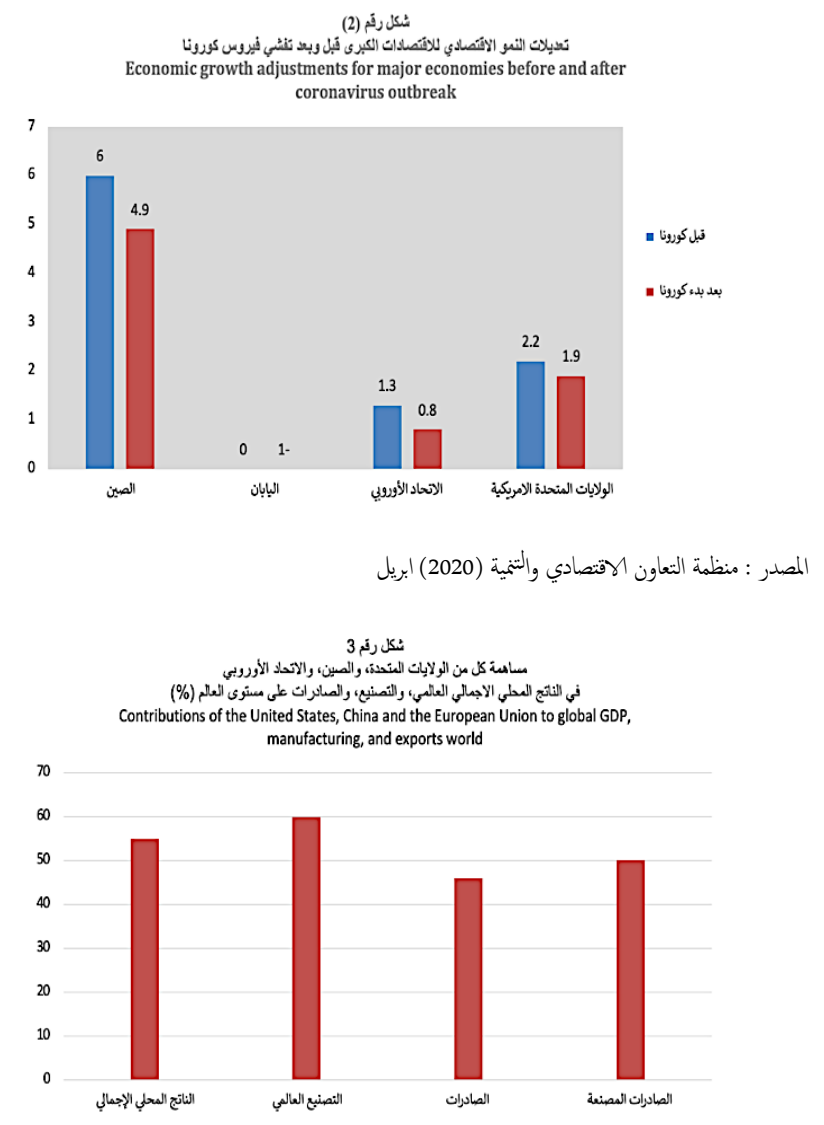

Sources: World Bank (2020), World Databank.
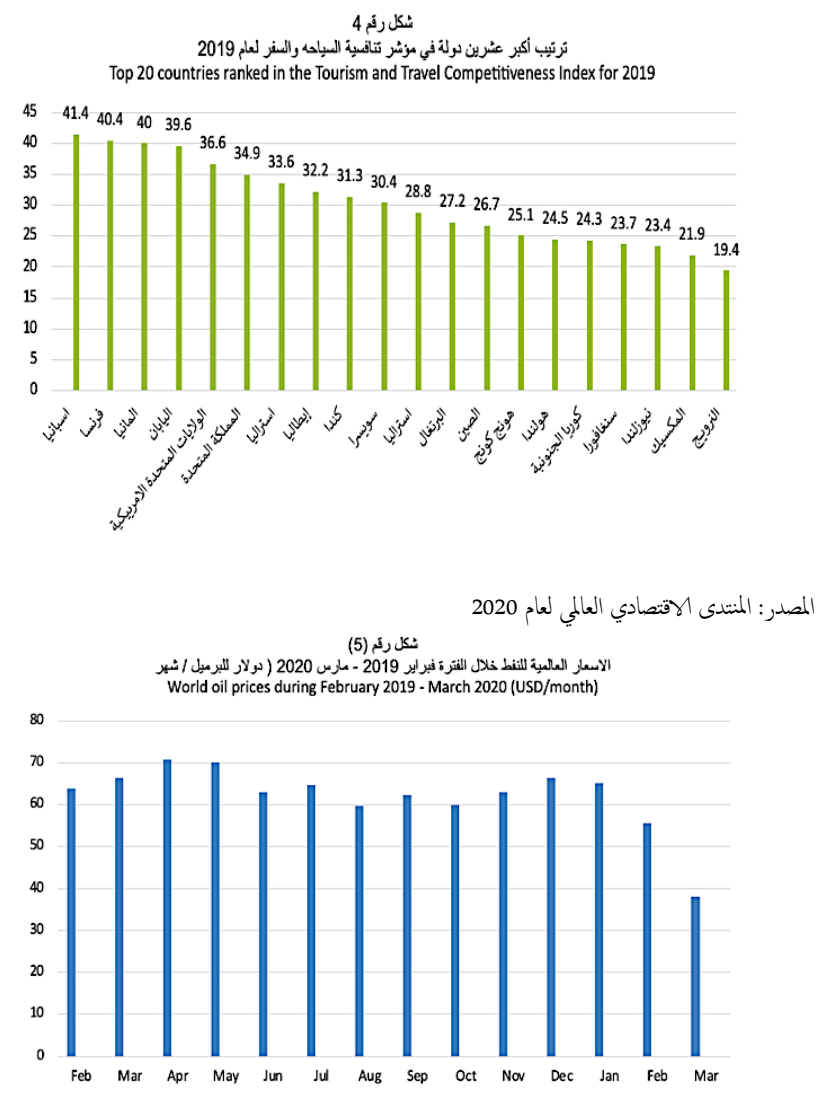

المصدر: منظمة الأططار المصدرة للنفط (2020)
18. European Central Bank (2020), "Our response to the coronavirus emergency”. Available at: https://www.ecb.europa.eu/home/html/index.en.html

19. Farid Zakaria,The Post American World and the Rise of the Rest ) Penguin Books Limited, 2011)

20. https://thedispatch.com/p/the-china-problem

21. https://thedispatch.com/p/the-china-problem-extends-well-beyond

22. https://thedispatch.com/p/the-china-problem-extends-well-beyond.

23. Edward N. Luttwak The Rise of China vs. the Logic of Strategy),Harvard University Press,, 2012).

24. The Communist Manifesto) Chiron Academic Press - The Original Authoritative,(Chiron Academic Press; 2016).

25. Foreign Affairs How The world will Look after The Coronavirus (Pandemic Mars 2020)

26. Globalization and Its Discontents Revisited: Anti-Globalization in the Era of Trump, W. W. Norton \& Company; 1 edition (November 28, 2017).

27. trump-protectionism-nationalism-globalization-killingcoronavirus/12/03/2020/com.foreignpolicy://http

28. March 2020 , Politico, fight coronavirus in Italy help to fails Europe, Deutsch Jillian and Paun Carmen, Herszenhorn. M David/17responses-coronavirus-control-better-aimseu/article/eu.politico.www://https:

29. Robert Nozick Anarchy, State, and UtopiaAudible Audiobook Unabridged ,Kevin Stillwell (Narrator), Hachette Audio, 2018).

30. John Gray, Liberalism, (Open University Press, 1986).

31. Robert 'Bob' Maginnis: https://www.facebook.com/robert.l.maginnis/posts/1021823330059 8618

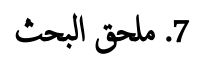

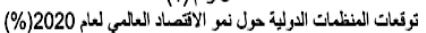
(\%) International organizations forecast for global economic growth for 2020

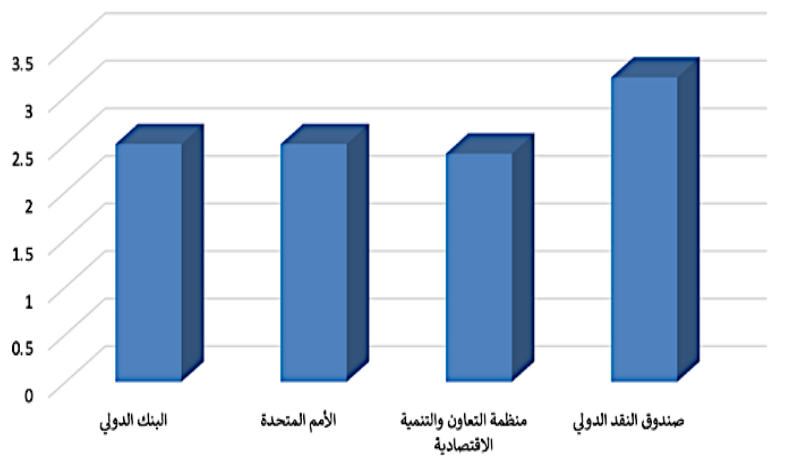

المصدر: من إعداد الباحث بالرجوع المى التقارير الختلفة للمنظلات الدولية (2020) 


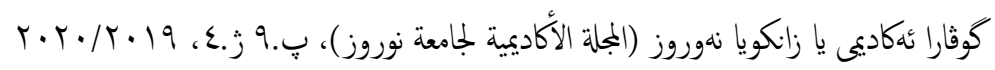

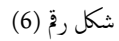

فرضيات عدد العاطلين عن العمل بسبب تنشي فيروس كررونا (مليون عاطل)

Assumptions of the number of unemployed due to the outbreak of coronavirus

(1 million unemployed)

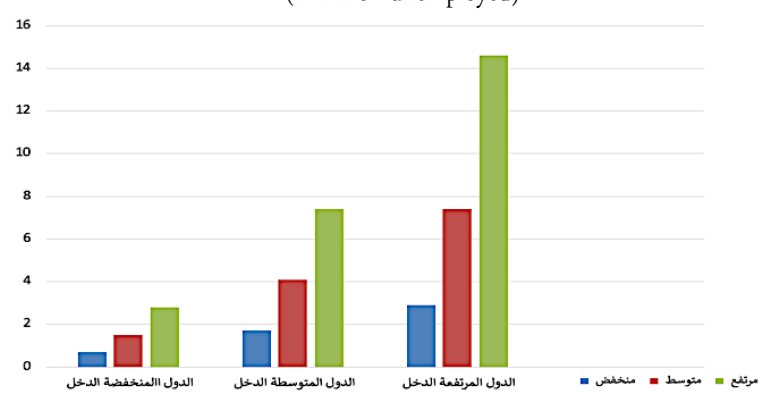

Source: ILO (2020), "How will COVID-19 affect the world of work", March. 